\title{
TITLE:
}

\section{ON THE NOCTURNAL BEHAVIOR OF TYLOS GRANULATUS MIERS (CRUSTACEA : ISOPODA)}

\author{
AUTHOR(S): \\ Imafuku, Michio
}

\section{CITATION:}

Imafuku, Michio. ON THE NOCTURNAL BEHAVIOR OF TYLOS GRANULATUS MIERS (CRUSTACEA : ISOPODA). PUBLICATIONS OF THE SETO MARINE BIOLOGICAL LABORATORY 1976, 23(3-5): 299-340

ISSUE DATE:

1976-10-30

URL:

http://hdl.handle.net/2433/175933

RIGHT: 


\title{
ON THE NOGTURNAL BEHAVIOR OF TYLOS GRANULATUS MIERS (CRUSTACEA: ISOPODA $)^{1)}$
}

\author{
Mrahio IMAFUKU \\ Laboratory for Plant Ecological Studies, Faculty of Science, Kyoto University \\ With Text-figures $1-18$
}

\begin{abstract}
The physiological and ecological aspects of the nocturnal activity of Tylos granulatus was investigated by natural observations and laboratory experiments that brought about the following results:

1. Tylos granulatus inhabits the pebbly beach, in the part higher than the level of respective high water, especially richly under stranded matters. It is nocturnal, gathering on the stranded materials at night but hiding itself in spaces among pebbles in the daytime.

2. On the studied beach, the temperature is higher in the daytime than at night, sometimes over $35^{\circ} \mathrm{C}$ in the daytime but below $30^{\circ} \mathrm{C}$ at night in the summer season. The humidity is higher at night. As the temperature of the hiding space is rather mild even in the daytime as compared with that of the exterior, Tylos can keep itself in the mild circumstances throughout the day by its nocturnal behavior.

3. Tylos is photopositive to lower light and can survive more than 2 days under the exposure to a bright light of ca. 10000 lux in the moist state. Its normal activity is displayed in the temperature range of 20 to $30^{\circ} \mathrm{C}$ and the critical temperature is found at about $45^{\circ} \mathrm{C}$ in the moist state. It survives longer in the highly humid condition and will be killed in 2 hours when it is exposed to the natural daytime condition on the beach in summer, though it can survive more than 4.5 hours if watered.

4. The activity rhythm of Tylos is controlled by the cycle of light, temperature and humidity and follows either of any two cycle according to the applied temperatures, when they are given coordinately with each other.

These results seem to explain the nocturnal activity of Tylos as an adaptation to the terrestrial life in relation to water conservation. Lastly, some speculation is made as to the development of the nocturnal activity of this animal on the above-mentioned explanation and the results of observations in the field and the laboratory.
\end{abstract}

\section{Contents}

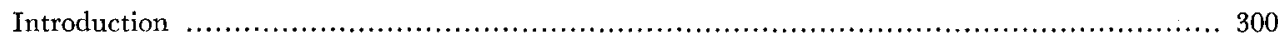

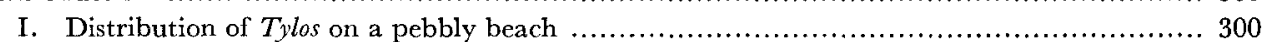

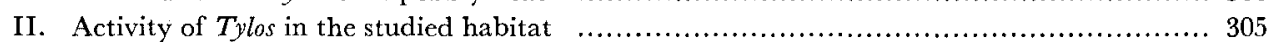

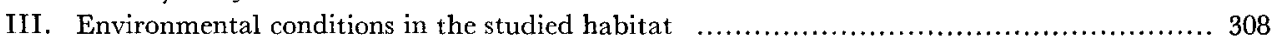

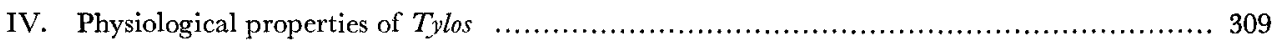

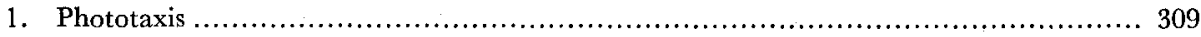

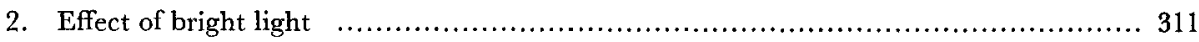

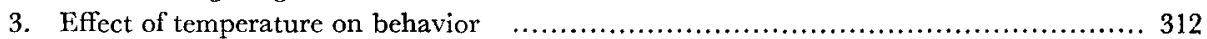

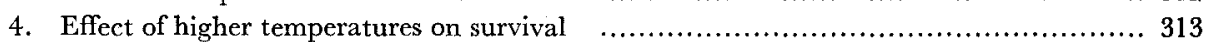

5. Selection of sizes of substratum elements and humid conditions . ....................... 315

1) Contributions from the Seto Marine Biological Laboratory, No. 629.

Publ. Seto Mar. Biol. Lab., XXIII (3/5), 299-340, $1976 . \quad$ (Article 23) 


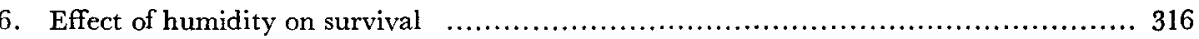

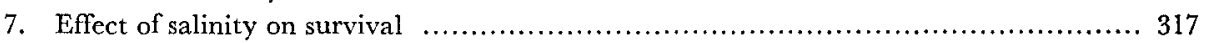

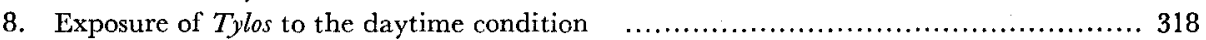

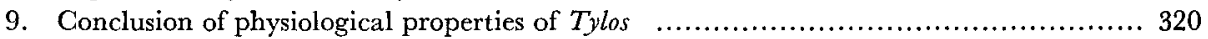

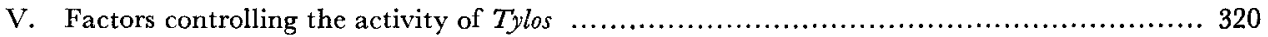

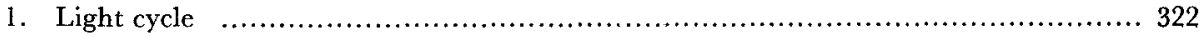

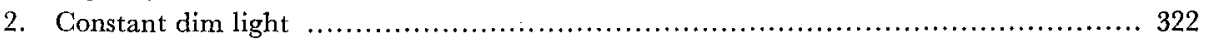

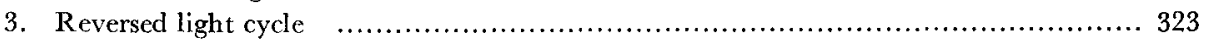

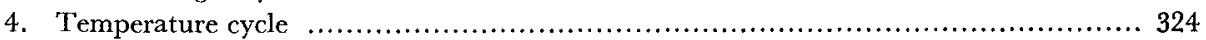

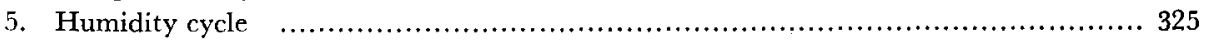

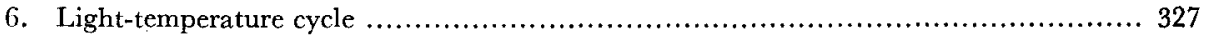

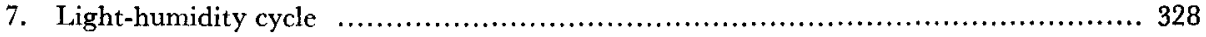

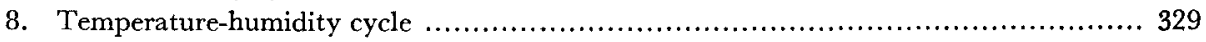

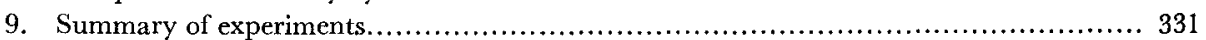

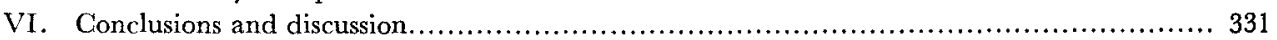

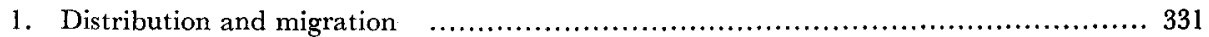

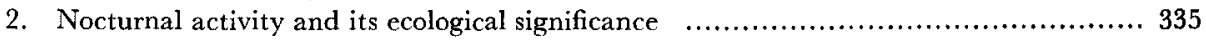

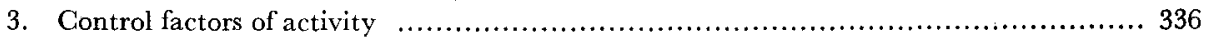

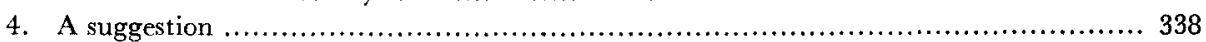

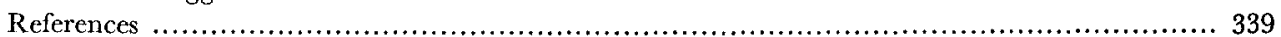

\section{Introduction}

The biota on the earth has mostly been subjected to a rigidly constant fluctuation of physical environmental factor, light, and to relatively unstable ones of such factors as temperature, humidity and so on, all caused by the earth rotation. As the behavioral and physiological activities of organisms living in such circumstances are more or less affected by these factors, any regular changes in activities corresponding with environmental factors are expected to be of a great biological significance. Here, in order to clarify the biological significance of nocturnal activity and to show environmental factors controlling this activity, Tylos granulatus Miers was observed and experimented with for its conspicuous noctivagation.

Tylos granulatus is a terrestrial isopod living on pebbly to sandy beaches. The nocturnal activity of this animal has been studied already by Ondo and Kensley. Ondo (1952) reported that Tylos granulatus was active at night and later (1953) suggested that this activity was of an endogenous nature and further (1954) that the activity pattern was different between the young and adult animals. While, Kensley (1974) found by night observations in nature, that the nocturnal activity of Tylos granulatus was affected by tidal conditions and suggested the tidal and lunar month components in this activity.

The present paper is to show mainly the results of observations and experiments designed to analyze more closely the effects of respective environmental factors, not yet referred to by these researchers, on the nocturnal behavior of this isopod.

\section{Distribution of Tylos on a Pebbly Beach}

Tylos granulatus is known living on beaches all over Japan composed of pebbles 
and sand. In this study, the distribution of this isopod was investigated on a pebbly beach (Fig. 15) at the tip of Cape Banshozaki situated west of the Seto Marine Biological Laboratory (Fig. 1), as this animal was found there most abundantly in the vicinities of the laboratory. This beach faces the sea northwestwards, but is surrounded by rocky cliffs along the other sides. The substratum was mainly composed of pebbles of various sizes in the lower part, but substratum elements diminishes the size upwards to pebbles, gravels and at last to sand near the foot of cliffs. The recess of this beach is covered by green plants, as a drainage terminates there. Many stranded matters such as wood pieces, algae and various kinds of trash are generally found scattered on the beach.

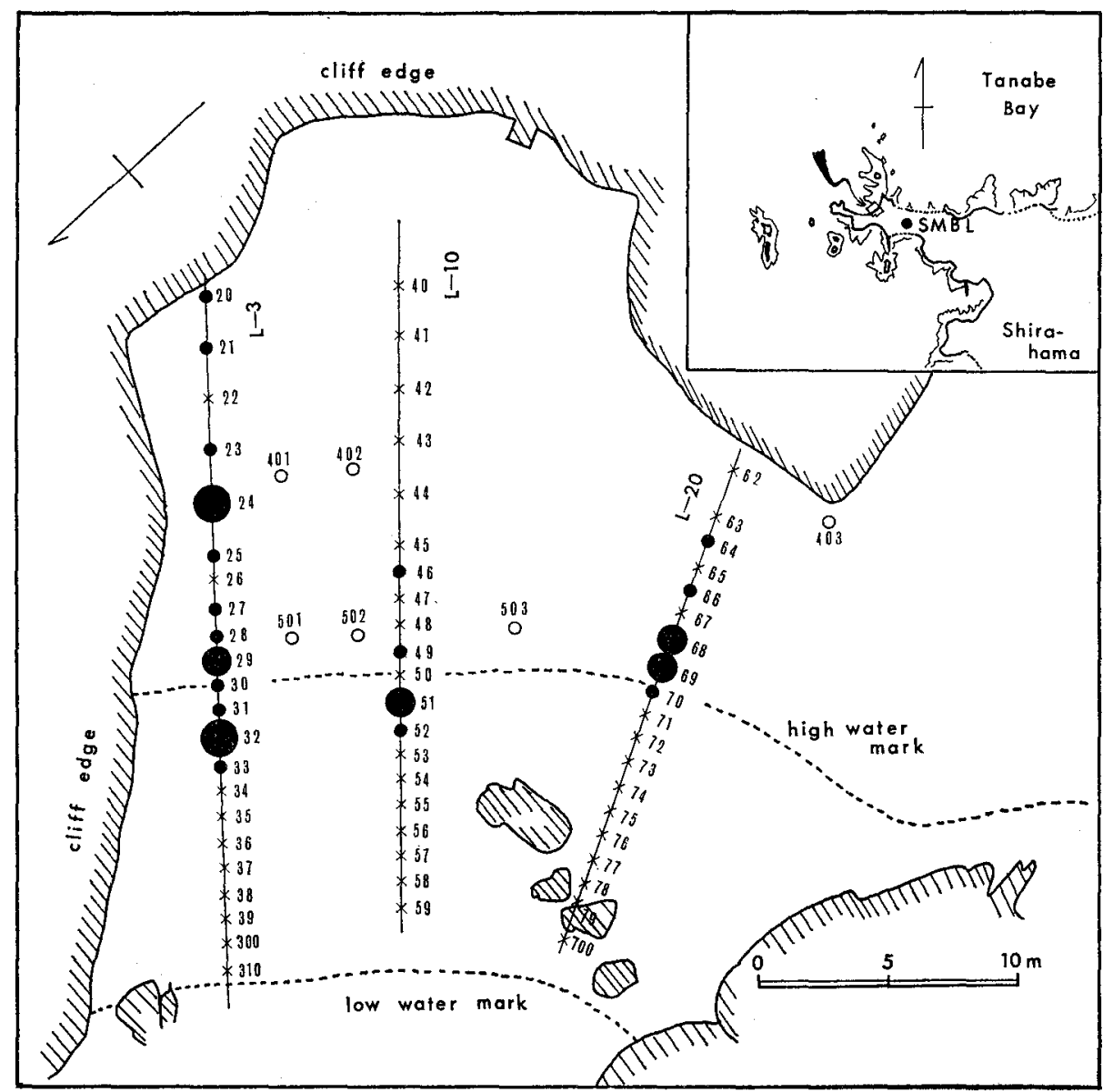

Fig. 1. The distribution of Tylos granulatus Miers on a pebbly beach, the location of which in Shirahama is shown in the inset.

Stations were set at intervals of $1-2 \mathrm{~m}$ on 3 transecting lines $(\mathrm{L}-3, \mathrm{~L}-10$ and $\mathrm{L}-20)$ each extending from the low water mark up to the landside edge of the beach. Cross, small, medium and large solid circles indicate respectively the occurrences of $0,1-5,6-10$ and more than 11 animals in a sample obtained with a cylinder, $90 \mathrm{~mm}$ in diameter and $93 \mathrm{~mm}$ in height.

For stations 401-403 and 501-503, see Table 2. 
Stations were set at intervals of 1 to 2 meters on three transecting lines $(\mathrm{L}-3$, L-10 and $\mathrm{L}-20$ ), starting respectively in the supratidal zone $3 \mathrm{~m}, 10 \mathrm{~m}$ and $20 \mathrm{~m}$ apart from the cliff foot, running down the beach straight across the intertidal zone and ending just near the low water mark (Fig. 1). At each station, while the beach was exposed, pebbles and gravels from the surface to about $9 \mathrm{~cm}$ deep were sampled with a bottomless brass cylinder, $90 \mathrm{~mm}$ in diameter and $93 \mathrm{~mm}$ in height, by inserting the cylinder into the substratum, removing pobbles around it and closing the cylinder bottom with a plate. This method was found almost sufficient to obtain the animals hiding themselves among wet pebbles and gravels beneath the surface dried pebbly stratum. When the dried stratum was rather thick, though rarely, at some stations consisting mainly of larger pebbles or cobbles, some dried pebbles were removed from the surface before sampling. The sample was spread on a tray and Tylos was sorted out carefully by the naked eye. Another method was adopted to treat some samples; a 5\% solution of ethanol was poured on the sample spread on the tray to chase animals to come out; by this method, however, only smaller animals came out of the sample in a few minutes, while larger ones were apt to remain inside the sample. Sampling was made in the daytime on 5th (stations 25-34, 45-54), 9th (stations 64-79, 700), 24th (stations 35-39, 300, 310, 55-59) and 25th (stations 20-24, $40-44,62-63)$ of September, 1973.

The number of individuals of Tylos held in each sample is shown exactly in Table 1 and by comparative marks in Fig. 1. From these table and figure, it is found that Tylos was distributed from the upper interdidal to supratidal zone, most abundantly around the high water mark, the level of which in the spring tide can be seen rather easily as a small ridge on the beach, left by wave action during the spring tide and is indicated as $\mathrm{Om}$ in Table 1 and by a dotted line in Fig. 1. Sizes of collected Tylos and substratum elements at each station are given in Table 1. The animals larger than $10 \mathrm{~mm}$ in length were limited in the supratidal zone, while those smaller than $5 \mathrm{~mm}$ were found abundantly in the upper intertidal zone. Probably this may be attributed to the behavior that the larval liberation is seemingly carried out near the high water mark. No clear correlation was found between the number of animals obtained and the grain size, as Tylos was obtained at stations of larger substratum clements (stations 24,64) as well as at those of smaller elements (stations 29, 69).

As Tylos appeared at stations 31-33, 51 and 52 in the upper intertidal zone, it might be thought that these results indicate that the animal is distributed in the range covered by sea water at high tide. However, the above-mentioned stations were seemingly situated above the level of the preceding high tide, when sampling at these stations were made during the neap tide on September 5th, 1973 at the lunar age of 8.0 days. The high tide mark should be a little lower in the neap tide. In order to make clear the relation between the high tide level and the distribution of Tylos at sampling, further samplings were made on September 23 at the lunar age of 26.0 days, especially paying attention to confirm the level of the preceding high tide, which was actually learned by discriminating the wrack. Five stations were set on each of three parallel lines respectively at levels of $-3 \mathrm{~m},-2 \mathrm{~m}, 0 \mathrm{~m},+1.5 \mathrm{~m}$ and 
Table 1. The size of animals and substratum elements at respective stations shown in Fig. 1.

\begin{tabular}{|c|c|c|c|c|c|c|c|c|c|c|c|c|c|c|c|c|c|c|c|c|c|c|c|}
\hline \multirow{3}{*}{$\begin{array}{l}\text { Distance }(m) \text { from } \\
\text { High Water Mark } \\
\text { of Spring Tide }(0)\end{array}$} & \multicolumn{8}{|c|}{$\mathrm{L}-3$} & \multicolumn{7}{|c|}{$\mathrm{L}-10$} & \multicolumn{8}{|c|}{$\mathrm{L}-20$} \\
\hline & \multirow[b]{2}{*}{ Station } & \multicolumn{4}{|c|}{ Animal Size } & \multicolumn{3}{|c|}{$\begin{array}{c}\text { Element Size } \\
(\%)\end{array}$} & \multirow[b]{2}{*}{ Station } & \multicolumn{3}{|c|}{ Animal Size } & \multicolumn{3}{|c|}{$\begin{array}{c}\text { Element Size } \\
(\%)\end{array}$} & \multirow{2}{*}{ Station } & \multicolumn{4}{|c|}{ Animal Size } & \multicolumn{3}{|c|}{$\begin{array}{c}\text { Element Size } \\
(\%)\end{array}$} \\
\hline & & $\begin{array}{l}\text { Total } \\
\text { Num. }\end{array}$ & $\begin{array}{l}0-5 \\
\mathrm{~mm}\end{array}$ & $\begin{array}{l}5-10 \\
\mathrm{~mm}\end{array}$ & $\begin{array}{l}10- \\
\mathrm{mm}\end{array}$ & $\begin{array}{l}0-2 \\
\mathrm{~mm}\end{array}$ & $\begin{array}{l}2-6 \\
\mathrm{~mm}\end{array}$ & $\begin{array}{l}6- \\
\mathrm{mm}\end{array}$ & & $\begin{array}{l}\text { Total } \\
\text { Num. }\end{array}$ & $\begin{array}{l}0-5 \\
\mathrm{~mm}\end{array}$ & $\begin{array}{l}5-1010- \\
\mathrm{mm} \mathrm{mm}\end{array}$ & $\begin{array}{l}0-2 \\
\mathrm{~mm}\end{array}$ & $\begin{array}{l}2-6 \\
\mathrm{~mm}\end{array}$ & $\begin{array}{c}6- \\
\mathrm{mm}\end{array}$ & & $\begin{array}{l}\text { Total } \\
\text { Num. }\end{array}$ & $\begin{array}{l}0-5 \\
\mathrm{~mm}\end{array}$ & $\begin{array}{l}5-10 \\
\mathrm{~mm}\end{array}$ & $\begin{array}{l}10- \\
\mathrm{mm}\end{array}$ & $\begin{array}{l}0-2 \\
\mathrm{~mm}\end{array}$ & $\begin{array}{l}2-6 \\
\mathrm{~mm}\end{array}$ & $\begin{array}{c}6- \\
\mathrm{mm}\end{array}$ \\
\hline+15 & 20 & 3 & & 1 & 2 & 38 & 29 & 33 & 40 & 0 & & & 69 & 14 & 17 & & & & & & & & \\
\hline+13 & 21 & 5 & 1 & & 4 & 43 & 42 & 15 & 41 & 0 & & & 60 & 15 & 25 & & & & & & & & \\
\hline$+10 \sim 11$ & 22 & 0 & & & & 37 & 23 & 40 & 42 & 0 & & & - & 一 & - & 62 & 0 & & & & 54 & 12 & 34 \\
\hline$+8 \sim 9$ & 23 & 5 & & 4 & 1 & - & - & - & 43 & 0 & & & 41 & 24 & 35 & 63 & 0 & & & & 51 & 16 & 33 \\
\hline$+6 \sim 7$ & 24 & 16 & 11 & & 5 & 27 & 25 & 48 & 44 & 0 & & & 20 & 21 & 59 & 64 & 2 & & 2 & & 7 & 24 & 69 \\
\hline+5 & 25 & 2 & & 2 & & 85 & 15 & 0 & 45 & 0 & & & 68 & 28 & 4 & 65 & 0 & & & & 20 & 28 & 52 \\
\hline+4 & 26 & 0 & & & & 91 & 8 & 1 & 46 & 1 & & 1 & - & - & - & 66 & 4 & & 1 & 3 & 87 & 12 & 1 \\
\hline+3 & 27 & 2 & & 1 & 1 & 90 & 9 & 1 & 47 & 0 & & & 58 & 36 & 6 & 67. & 0 & & & & 61 & 32 & 7 \\
\hline+2 & 28 & 1 & 1 & & & 82 & 17 & 1 & 48 & 0 & & & 89 & 10 & 1 & 68 & 6 & 1 & 5 & & 56 & 30 & 14 \\
\hline+1 & 29 & 9 & 1 & 6 & 2 & 73 & 12 & 15 & 49 & 2 & & 2 & 94 & 6 & 0 & 69 & 7 & 1 & 4 & 2 & 79 & 18 & 3 \\
\hline 0 & 30 & 2 & & 2 & & 92 & 7 & 1 & 50 & 0 & & & 93 & 6 & 1 & 70 & 5 & & 5 & & 94 & 6 & 0 \\
\hline-1 & 31 & 2 & 1 & 1 & & 80 & 20 & 0 & 51 & 8 & & 8 & 95 & 4 & 1 & 71 & 0 & & & & 83 & 11 & 6 \\
\hline-2 & 32 & 17 & 17 & & & 65 & 35 & 0 & 52 & 2 & 2 & & 55 & 41 & 4 & 72 & 0 & & & & 21 & 44 & 35 \\
\hline-3 & 33 & 1 & 1 & & & 50 & 49 & 1 & 53 & 0 & & & 16 & 45 & 39 & 73 & 0 & & & & 17 & 40 & 43 \\
\hline-4 & 34 & 0 & & & & 36 & 42 & 22 & 54 & 0 & & & 38 & 31 & 31 & 74 & 0 & & & & 32 & 39 & 29 \\
\hline-5 & 35 & 0 & & & & 38 & 33 & 29 & 55 & 0 & & & 22 & 29 & 49 & 75 & 0 & & & & 57 & 24 & 19 \\
\hline-6 & 36 & 0 & & & & 一 & - & - & 56 & 0 & & & 53 & 21 & 26 & 76 & 0 & & & & - & - & - \\
\hline-7 & 37 & 0 & & & & 43 & 51 & 6 & 57 & 0 & & & 35 & 56 & 9 & 77 & 0 & & & & 53 & 36 & 11 \\
\hline-8 & 38 & 0 & & & & 63 & 21 & 16 & 58 & 0 & & & - & - & - & 78 & 0 & & & & 72 & 13 & 15 \\
\hline-9 & 39 & 0 & & & & 38 & 49 & 13 & 59 & 0 & & & 92 & 7 & 1 & 79 & 0 & & & & 79 & 5 & 16 \\
\hline-10 & 300 & 0 & & & & 60 & 28 & 12 & & & & & & & & 700 & 0 & & & & 57 & 27 & 16 \\
\hline-11 & 310 & 0 & & & & 84 & 15 & 1 & & & & & & & & & & & & & & & \\
\hline
\end{tabular}


$+2.5 \mathrm{~m}$. The level of $-3 \mathrm{~m}, 3 \mathrm{~m}$ apart seawards from the high water mark of spring tide, was characterized by complete absence of any stranded matters and showed that this level had been submerged at the preceding high tide. The level of $-2 \mathrm{~m}$ was the water edge at the preceding high tide, as this was suggested by freshly stranded algae. The level of $0 \mathrm{~m}$ was the high water mark of spring tide. The level of $+1.5 \mathrm{~m}$ was covered with dry algae which seemingly had been washed up there at some previous rough water. The level of $+2.5 \mathrm{~m}$ was quite devoid of any stranded matters. The number of animals obtained at each station is shown in Fig. 2, from which it is

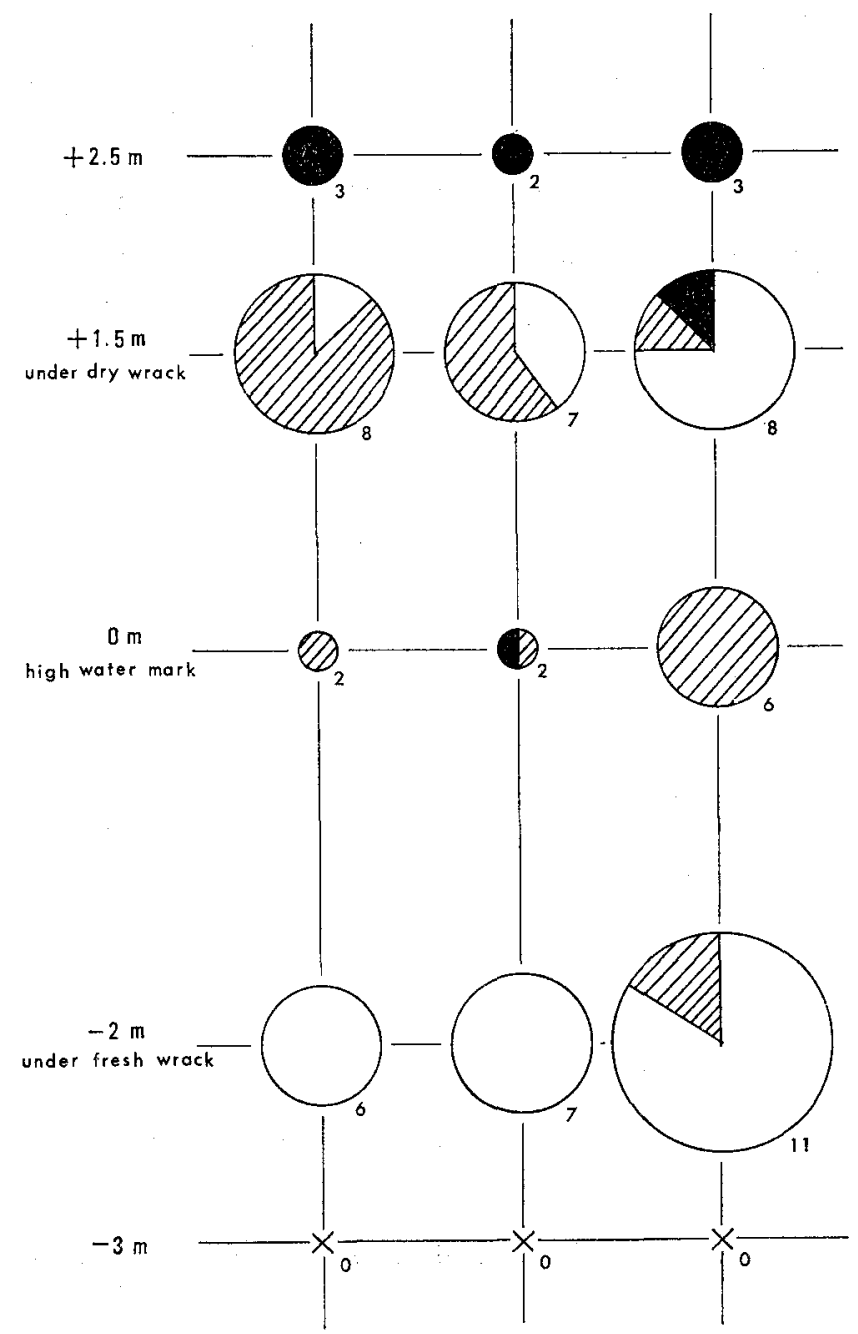

Fig. 2. Occurrences of Tylos at different levels.

Five stations were set at levels $-3 \mathrm{~m},-2 \mathrm{~m}, 0 \mathrm{~m},+1.5 \mathrm{~m}$ and $+2.5 \mathrm{~m}$ on each of three parallel lines; respective levels showing the distance from the high water mark of the spring tide, + landwards and - seawards. The number of animal individuals shown in arabic number and also by the size of circles (by cross when absent). The size of animals is graded into black $(10-15 \mathrm{~mm})$, striped $(5-10 \mathrm{~mm})$ and white $(0-5 \mathrm{~mm})$. 
clear that no animal appeared at the stations below the level of the preceding high tide and that larger animals increased at higher levels. The distribution of Tylos is thus thought to be limited to the area above the level of the preceding high tide. Therefore, Tylos may change the lower limit of the distribution on the beach in relation with the level of high tide, which fluctuates between the neap and spring tides.

In the course of observations, it seemed that the animals were more abundant in the places covered with wracks rather than those quite free from any stranded matters. To confirm this point, two station groups (stations 401-403 and stations 501-503) were set arbitrarily respectively in the places with or without stranded matters, as shown in Fig. 1. Samplings were made at each station on October 31 in the same way as mentioned previously, but removing stranded matters when they existed. The number of animal individuals are shown in Table 2. Evidently much more animals were found under stranded matters than among pebbles at stations free from the wrack. In addition, the animals obtained at stations with stranded matters included relatively larger individuals.

Table 2. Number of animal individuals under stranded matters and among pebbles. For the situation of respective stations see Fig. 1. As to the relation between the animal density and the wrack, refer to Fig. 2, too.

\begin{tabular}{|c|c|c|c|c|c|c|c|}
\hline \multirow{2}{*}{ Substratum } & \multirow{2}{*}{ Stations } & \multirow{2}{*}{$\begin{array}{l}\text { Total Number } \\
\text { of Animals }\end{array}$} & \multicolumn{5}{|c|}{ Animal Size (mm) } \\
\hline & & & $0-5$ & $5-10$ & $10-15$ & $15-20$ & 20 \\
\hline \multirow{3}{*}{$\begin{array}{l}\text { Under the } \\
\text { Stranded } \\
\text { Matters }\end{array}$} & 401 & 16 & 7 & 2 & 4 & 3 & \\
\hline & 402 & 21 & 10 & 4 & 6 & 1 & \\
\hline & 403 & 30 & 8 & 4 & 8 & 9 & 1 \\
\hline \multirow{3}{*}{$\begin{array}{l}\text { Among } \\
\text { Pebbles }\end{array}$} & 501 & 0 & & & & & \\
\hline & 502 & 1 & & 1 & & & \\
\hline & 503 & 1 & 1 & & & & \\
\hline
\end{tabular}

It may be concluded from these observations, that Tylos granulatus living on the studied pebbly beach is distributed in the area higher than the high tide level of respective tides, especially richly under stranded matters, but without any clear correlation with the size of substratum elements. Furthermore, in respective habitats they are rich in the wet space just beneath the surface dry pebbly stratum.

\section{Activity of Tylos in the Studied Habitat}

From the above-observations, it was found that Tylos granulatus were hiding themselves among pebbles or under stranded matters in the daytime. On the other hand, it has been known that this animal is active at night, coming out on the beach surface to gather on stranded matters. To see this actually some brief observations were made in the daytime and at night. Almost no animals were found in the daytime on either the surface of the pebbly substratum or stranded matters, except for small animals of about $3 \mathrm{~mm}$ in body length, which were rarely found clinging to 
algae just stranded here and there around the high water mark. These small individuals seemingly might be liberated there at the preceding night. While, at night, many animals of various sizes were found gathering on stranded algae (Fig. 16) or crawling on the beach surface.

In order to compare the activity at night with that in the daytime, stranded algae were collected on the beach, especially from around the high water mark at night from $21: 00$ to 24:00 and in the daytime from $11: 00$ to 14:00, and the animals hidden in them were examined. Dominant algae stranded in the period of investigation from September 12 to October 15 were Sargassum micracanthum, Hypnea saidana, Jania decussato-dichotoma, Chondrococcus hornemanii, Acanthophora orientalis, Sargassum thumbergii, Dictyota dichotoma, Laurencia sp., Actinotrichia fragilis and Galaxaura papillata, arranged in the order of abundance. Algae of $14 \mathrm{~g}$ to $133 \mathrm{~g}$ in dry weight were collected for each examination. The number of animals found in each sample and the number of individuals per $50 \mathrm{~g}$ of dry algae calculated on the number actually read are shown in Table 3. It is seen from this table, that the animals were obtained from both the night and daytime samples, though much less from the daytime samples and the animals from the night samples were larger than those from the daytime samples. On October 14, some animals of $10 \mathrm{~mm}$ or more in length were obtained from the daytime samples; this was probably attributed to the fact that the sample was composed of a large cluster of Sargassum micracanthum and therefore enough hiding spaces for animals were rendered. Therefore, simple collection of stranded algae was insufficient to see the actual fluctuation in the activity. Although smaller animals were obtained from both the night and daytime samples, larger animals more than $15 \mathrm{~mm}$ were found exclusively from the night samples. This may be explained by the results of the laboratory experiments made by Ondo (1954) with the same species, that large animals showed a clear nocturnal activity, while the smaller were active throughout day and night, though not always constant in activity.

Table 3. Number of animals obtained from night and daytime samples of algae.

Figures in parentheses are number of individuals per $50 \mathrm{~g}$ of dry algae, calculated on the actual data.

\begin{tabular}{|c|c|c|c|c|c|c|c|c|c|}
\hline \multirow{2}{*}{ Samples } & \multirow{2}{*}{\multicolumn{2}{|c|}{ Date }} & \multirow{2}{*}{$\begin{array}{c}\text { Sampled } \\
\text { Algae in Dry } \\
\text { Weight }(\mathrm{g})\end{array}$} & \multirow{2}{*}{$\begin{array}{c}\text { Total } \\
\text { Number of } \\
\text { Animals }\end{array}$} & \multicolumn{5}{|c|}{ Animal Size (mm) } \\
\hline & & & & & $0-5$ & $5-10$ & $10-15$ & $15-20$ & $20-25$ \\
\hline \multirow{5}{*}{ Night } & Sept. 1 & & 28.0 & $30(53.6)$ & $8(14.3)$ & $16(28.6)$ & $4(7.1)$ & $1(1.8)$ & $1(1.8)$ \\
\hline & & 3 & 38.3 & $12(15.7)$ & $6(7.8)$ & $1(1.3)$ & $2(2.6)$ & $2(2.6)$ & $1(1.3)$ \\
\hline & & 6 & 32.1 & $17(26.5)$ & $5(7.8)$ & $3(4.7)$ & $9(14.0)$ & & \\
\hline & Oct. 1 & 12 & 133 & $126(47.4)$ & $18(6.8)$ & $7(2.6)$ & $64(24.1)$ & $34(12.8)$ & $3(1.1)$ \\
\hline & & 14 & 74 & $28(18.9)$ & & $3(2.0)$ & $21(14.2)$ & $4(2.7)$ & \\
\hline \multirow{5}{*}{ Dry } & Sept. 1 & & 31.6 & $13(20.6)$ & $13(20.6)$ & & & & \\
\hline & & 14 & 44.0 & $28(31.8)$ & $28(31.8)$ & & & & \\
\hline & & 16 & 14.4 & $24(49.2)$ & $20(41.0)$ & $4(8.2)$ & & & \\
\hline & Oct. 1 & 14 & 119 & $25(10.5)$ & $14(5.9)$ & $9(3.8)$ & $2(0.8)$ & & \\
\hline & & 15 & 66 & $0(0.0)$ & & & & & \\
\hline
\end{tabular}


Table 4. Environmental condition in the habitat of Tylos and number of animals found there and at the time of environmental measurements in the daytime and at night.

Number of animals counted within 3 minutes walk on the beach is shown.

\begin{tabular}{|c|c|c|c|c|c|c|c|c|c|}
\hline \multirow{2}{*}{ Date } & & \multicolumn{2}{|c|}{$\begin{array}{l}\text { Temperature on } \\
\text { Pebble }\left({ }^{\circ} \mathrm{C}\right)\end{array}$} & \multicolumn{2}{|c|}{$\begin{array}{l}\text { Temperature under } \\
\text { Stranded Matter }\end{array}$} & \multicolumn{2}{|c|}{$\begin{array}{c}\text { Relative } \\
\text { Humidity }(\%)\end{array}$} & \multicolumn{2}{|c|}{$\begin{array}{c}\text { Number of } \\
\text { Animals }\end{array}$} \\
\hline & & day & 'night & day & night & day & night & day & night \\
\hline \multirow[t]{3}{*}{ '73 Sep. } & 12 & 36.5 & 24.5 & & & & & & \\
\hline & 19 & 34.0 & 22.5 & & & & & & \\
\hline & 23 & 29.7 & 23.0 & & & & & & \\
\hline \multirow{5}{*}{ Nov. } & 8 & 25.5 & 17.0 & & & 60 & 95 & & \\
\hline & 10 & 21.0 & 13.0 & & & 54 & 68 & & \\
\hline & 15 & 22.5 & 13.0 & 15.0 & 14.4 & 31 & 79 & 0 & $50 \div$ \\
\hline & 16 & 22.0 & 18.5 & 15.2 & 16.5 & 51 & 57 & 0 & $50+$ \\
\hline & 17 & 19.0 & 14.0 & 16.5 & 14.9 & 50 & 51 & 0 & \\
\hline \multirow[t]{3}{*}{ Dec. } & 7 & 11.0 & 8.5 & 11.9 & 8.5 & 61 & 69 & 0 & 0 \\
\hline & 8 & 11.0 & 9.5 & 10.5 & 9.5 & 51 & 65 & 0 & 1 \\
\hline & 9 & 11.5 & 3.0 & 9.2 & 7.2 & 52 & 62 & 0 & 0 \\
\hline \multirow{2}{*}{ '74 Feb. } & 20 & 17.5 & 8.5 & 13.5 & 10.1 & 68 & 57 & 0 & 5 \\
\hline & 21 & 16.0 & 5.0 & 10.4 & 9.8 & 54 & 79 & 0 & 0 \\
\hline \multirow[t]{6}{*}{ Mar. } & 5 & 23.5 & 15.5 & 13.3 & 13.8 & 58 & 85 & 0 & $100+$ \\
\hline & 7 & 18.5 & 10.0 & 16.1 & 12.0 & 82 & 82 & 0 & 15 \\
\hline & 8 & 20.5 & 9.0 & 12.3 & 10.7 & 45 & 58 & 0 & 0 \\
\hline & 20 & 18.5 & 5.0 & 10.5 & 9.6 & 36 & 58 & 0 & 0 \\
\hline & 21 & 23.5 & 10.0 & 10.5 & 11.5 & 37 & 88 & 0 & 50 \\
\hline & 22 & 17.5 & 7.0 & 11.1 & 10.0 & 48 & 68 & 0 & 0 \\
\hline \multirow[t]{6}{*}{ Apr. } & 2 & 23.5 & 8.5 & 12.9 & 10.4 & 27 & 52 & 0 & 0 \\
\hline & 3 & 24.5 & 12.5 & 12.5 & 13.0 & 27 & 69 & 0 & 29 \\
\hline & 4 & 26.5 & 14.5 & 14.8 & 14.6 & 33 & 75 & 0 & 85 \\
\hline & 16 & 22.0 & 14.5 & 17.0 & 14.2 & 64 & 69 & 0 & 34 \\
\hline & 17 & 33.0 & 15.0 & 18.8 & 16.1 & 25 & 80 & 0 & 5 \\
\hline & 23 & 29.0 & 15.0 & 17.6 & 16.2 & 33 & 80 & 0 & 20 \\
\hline \multirow[t]{6}{*}{ May } & 4 & 35.5 & 19.5 & 23.5 & 20.1 & 30 & 87 & 0 & 0 \\
\hline & 5 & 33.0 & 16.5 & 22.2 & 16.9 & 37 & 63 & 0 & 2 \\
\hline & 6 & 28.0 & 15.0 & 19.1 & 17.0 & 37 & 70 & 0 & 8 \\
\hline & 21 & 22.5 & 21.5 & 22.4 & 21.6 & 100 & 100 & 0 & 78 \\
\hline & 22 & 25.5 & 20.5 & 24.4 & 21.1 & 81 & 96 & 0 & 51 \\
\hline & 23 & 31.0 & 20.5 & 22.5 & 21.0 & 50 & 91 & 0 & 82 \\
\hline \multirow[t]{3}{*}{ June } & 5 & 36.5 & 21.5 & 24.0 & 22.8 & 46 & 87 & 0 & $100+$ \\
\hline & 6 & 32.5 & 20.0 & 23.5 & 20.5 & 43 & 66 & 0 & 75 \\
\hline & 7 & 37.0 & 20.5 & 23.5 & 21.8 & 36 & 78 & 0 & $100+$ \\
\hline \multirow[t]{4}{*}{ July } & 3 & 37.0 & 25.5 & 28.4 & 25.1 & 58 & 92 & 0 & 25 \\
\hline & 12 & 33.0 & 23.0 & 27.8 & 25.0 & 60 & 88 & 0 & 68 \\
\hline & 17 & 37.5 & 27.0 & 27.3 & 27.0 & 58 & 89 & 0 & 24 \\
\hline & 19 & 42.5 & 28.0 & 30.0 & 27.5 & 42 & 75 & 0 & 43 \\
\hline \multirow[t]{3}{*}{ Aug. } & 5 & 37.0 & 27.0 & 32.0 & 30.5 & 57 & 89 & 0 & 5 \\
\hline & 6 & 46.0 & 28.5 & 36.5 & 30.8 & 34 & 89 & 0 & 18 \\
\hline & 8 & 38.0 & 26.0 & 29.3 & 28.5 & 51 & 85 & 0 & 105 \\
\hline
\end{tabular}


Concerning the activity of Tylos in the daytime and at night, another series of observations were made on the beach from November 1973 to August 1974. In these, the animals gathering on stranded matters or crawling on the beach surface, met with within every three minutes walk along the high water mark shown by rich materials freshly stranded, were recorded and environmental factors were measured at the same time (Table 4). The table shows that the animals were observed on stranded matters or on the beach surface limitedly at night. This does not always agree with the results of the previous examinations of collected wrack holding some small animals even in the daytime, as such small ones were hiding themselves inside the cluster of stranded algae or under their fronds and therefore undetected in such observations in the daytime.

Seasonally, the animals were inactive in winter when the temperature dropped below 8 to $10^{\circ} \mathrm{C}$ on the beach surface. Further, their activity seemed to be affected by tide and wind, as a great number of animals were observed immediately after the water began to retreat in some spring tides, though they were seemingly less active while the water remained high. Strong wind clearly suppressed their activity. Though no individuals were recorded in the daytime in Table 4, some were found, but rarely, coming out from among pebbles when the pebble surface got wet by rainfall just started. In such cases, many animals of different sizes appeared on the surface but soon went back beneath the pebbles in a few minutes; this seemed as if the animals were trying to move to better places at rain fall. The animals would appear on the surface, too, when their habitat was disturbed for instance by digging.

From these observations, it may be safely concluded that Tylos granulatus is nocturnal, gathering on stranded matters at night and hiding itself under these or among the pebbles in the daytime, though rainfall or some disturbance may make the animals temporarily active even in the daytime, and that the animals are inactive in winter when the temperature drops below 8 to $10^{\circ} \mathrm{C}$.

\section{Environmental Conditions in the Studied Habitat}

In considering the biological significance of the nocturnal activity of Tylos granulatus, it is indispensable to learn the environmental conditions in the habitat, especially their difference between day and night. Then, the temperature and humidity were measured just above the surface of the pebbly substratum and the temperature under stranded matters.

The atmospheric temperature and humidity $1-2 \mathrm{~cm}$ above the beach surface were measured with Assman's aspiration psychrometer and the temperature under stranded matters, which harbored many animals, was measured by inserting a liquid thermometer 10 to $15 \mathrm{~cm}$ deep inside. The measurements were made in the time 10:00 to 14:00 in the daytime and 22:00 to 1:00 at night; the results are given in Table 4. The temperature on the beach surface was always higher in the daytime than at night, the daytime temperature remained above $10^{\circ} \mathrm{C}$ throughout the year and seldom dropped below $35^{\circ} \mathrm{C}$ in summer. On the other hand, the night temperature 
on the beach surface dropped to $3^{\circ} \mathrm{G}$ in winter and never rose above $30^{\circ} \mathrm{G}$ even in summer. Thus, the temperature on the beach surface fluctuated greatly throughout the day, frequently the daily fluctuations of temperature attained to $10^{\circ} \mathrm{C}$ or more. While the temperature under stranded matters was relatively stable throughout the day, the daily fluctuations rarely reached more than $4^{\circ} \mathrm{C}$ even when the atmospheric temperature fluctuated greatly. Seemingly the daytime temperature under stranded matters rather resembled the night temperature on the beach surface. Relative atmospheric humidity on the beach surface was almost always higher at night than in the daytime, though the fluctuations were not so conspicuous on some days in winter. The relative humidity seldom exceeded $60 \%$ in the daytime and fell below $60 \%$ at night.

The temperature drop and the rise of relative humidity at night, seen in Table 4, accord with the general trends in the field. Here, however, it is interesting to note that the temperature differences were rather small between the hiding space of Tylos in the daytime and the air just above the beach surface at night. This may suggest that Tylos, that lives in the environment which might be expressed as a kind of small desert, especially in summer season, becomes nocturnal, as it can expose itself in a relatively mild circumstances, rather constantly with lower temperature and higher humidity at night.

Some animals were found hovering on the studied beach: the following birds were recorded: kites and crows met with frequently in the early morning and evening and rarely Monticola solitarius, Motacilla alba and Tringa hypoleucos in the daytime; toads probably seeking small creatures as food sometimes near the high water mark at night; sea turtles for laying eggs rarely at night in summer; small arthropods such as sand hoppers, sow bugs, earwigs at night and flies and spiders in the daytime. Of these animals birds and toads might be of some importance as predators for Tylos granulatus (see Discussion).

\section{Physiological Properties of Tylos}

Against the environmental factors in the habitat of Tylos granulatus, the physiological properties of the animal should be studied to understand wholly its nocturnal activity. Thus, the response and reaction to light, temperature and humidity were examined, as they were thought to affect greatly its activity.

\section{Phototaxis}

The nocturnal behavior of Tylos granulatus may suggest the negative phototaxis to escape from the light. Actually the animals prefer the darker sides when they are placed on a table in the daytime. However, a simple indoor experiment showing that some individuals of Tylos kept in a glass vessel were gathered together to the light source of a flash lamp at night, suggests that Tylos does not always escape from the light in every condition. Really, the positive phototaxis of this animal has been studied by some workers (Morita, quoted by Ondo, 1952; Iga, 1972). Thus, the present 
paragraph refers to the results of the experiments to investigate the response of this animal to the light of various intensities.

In the first experiment, a single individual of this animal was placed at the middle of a small passage which was $48 \mathrm{~cm}$ long, $3 \mathrm{~cm}$ wide, $2 \mathrm{~cm}$ high and lined with black paper on the bottom and walls, and was illuminated with a tungsten lamp from the side of either end. Each of eleven animals kept in a glass vessel containing some pebbles was experimented with two times to respective light intensities of $0,0.1,1$, 10,100 and $1000 \mathrm{lux}$, measured at the middle of the passage, at night (23:00-1:00) on October 26-27. The results are shown in Table 5A.

As a control, selection of direction of this animal was tested in complete darkness. The animals crawled in two directions almost equally in complete darkness, but in the illumination of 0.1 lux from the left they moved in the left direction. Such positive phototaxis was confirmed at 1, 10 and $100 \mathrm{lux}$, too. At these lower light

Table 5. Tactic behaviors of Tylos granulatus at different light intensities.

Experiments A: Eleven animals were each tested twice at respective light intensities of 0 , $0.1,1,10,100$ and 1000 lux at midnight of October 26.

A. Response of animals to light.

\begin{tabular}{crcr}
\hline \hline \multirow{2}{*}{ Light Intensity } & & Phototaxis & \\
\cline { 2 - 4 } Darkness & + & - & $+\%$ \\
\hline \multirow{2}{*}{0.1 lux } & 7 & 4 & 64 \\
& 5 & 6 & 45 \\
1 & 11 & 0 & 100 \\
& 11 & 0 & 100 \\
10 & 9 & 2 & 82 \\
& 11 & 0 & 100 \\
100 & 10 & 1 & 91 \\
& 10 & 1 & 91 \\
1000 & 10 & 1 & 91 \\
& 8 & 3 & 73 \\
& 5 & 6 & 45 \\
\hline
\end{tabular}

Experiments B: The animals of different sizes were tested in the same way from 14:00 to 18:00 on October 29.

B. Percentage of photopositive behaviors.

\begin{tabular}{ccccc}
\hline \hline \multirow{2}{*}{ Light Intensity } & \multicolumn{4}{c}{ Body Size (mm) } \\
\cline { 2 - 5 } & $5-10(8)^{*}$ & $10-15(10)^{*}$ & $15-20(10)^{*}$ & $20-25(4)^{*}$ \\
\hline 0.1 lux & $88 \%$ & 70 & 70 & 100 \\
1 & 63 & 40 & 90 & 75 \\
10 & 100 & 80 & 50 & 75 \\
100 & 88 & 60 & 20 & 75 \\
1000 & 100 & 60 & 50 & 75 \\
\hline
\end{tabular}

* Numbers of animals tested. 
intensities, it was observed that an animal which was first crawling to the dark right side occasionally turned by $180^{\circ}$ to the left light source and kept its rapid crawling to the left end of the passage. Such behaviors show clearly that Tylos is photopositive to the light of lower intensities. On the other hand, when the light intensity was raised to 1000 lux, the animals moved in both the left and right directions equally. At this high light intensity, it seemed that the animal placed at the middle of the passage was unable to select the direction just after it evolved from its rolled state at handling and recovered its activity. Further, some animals pressed the body to the passage wall and sometimes stopped on the way to the light source as if to avoid going nearer. Such behaviors seem to indicate that Tylos is not always photopositive at the illumination of 1000 lux, even though it might select the direction toward the light source.

In the second and the last experiment, the selection of direction was tested with animal group in different size ranges, 8 individuals of $5-10 \mathrm{~mm}, 10$ individuals of $10-15 \mathrm{~mm}, 10$ individuals of $15-20 \mathrm{~mm}$ and 4 individuals of $20-25 \mathrm{~mm}$ long, all had been maintained in the laboratory for some days since they were collected on the beach. The method of experiment was the same as in the first experiment only excepting that an entrance to the passage was opened at the middle. The experiment was made from 14:00 to 18:00 on October 29. From the results of the experiment shown in Table 5B, it may be learned that smaller animals were almost photopositive even at higher light intensities, while the animals larger than $10 \mathrm{~mm}$ in length were only infrequently photonegative at relatively lower light intensities. As a whole, however, the results of this experiment seemed rather irregular as compared with those of the first experiment and did not always agree well with the latter. This might be attributed to the fact that the first experiment was performed at midnight, while the last in the afternoon still in the daytime. The animals might become photopositive at midnight but relatively insensitive to the light in the daytime. The fact that smaller animals were photopositive at higher light intensities may explain the field observation that smaller animals were observed gathering on freshly stranded algae in the daytime (p. 306). Thus, it may be safely concluded that Tylos granulatus behaves photopositively to lower light intensities at midnight.

\section{Effect of Bright Light}

Although the previous experiment showed that $T_{y}$ los did not always escape from the light, especially of lower intensities, the natural light intensity in the daytime is much higher than the illumination in the experiments. Therefore, it was examined if a light as bright as the daylight affected seriously this animal appearing on the beach surface only at night.

Ten animals were put in a box, $80 \mathrm{~mm} \times 80 \mathrm{~mm}$ in extent, $20 \mathrm{~mm}$ deep and covered with a transparent plastic lid, and illuminated continuously at 11500 lux with a $300 \mathrm{~W}$ flud lamp for 68 hours or more in total illuminated time, though interrupted three times for replacement of broken lamps. In order to keep the temperature inside the box at $25^{\circ} \mathrm{C}$, a water layer of $15 \mathrm{~cm}$ thick was set as a filter between the 
lamp and the box, which was further equipped with a ventilator for indraught of the fresh air.

The animals under illumination of a bright light changed their integument color into whitish. They sometimes gathered together at the holes for ventilation or crawled around on the box floor. Nine animals survived the time of experiment while one was killed by unknown cause. The animals survived were regarded as normal because they behaved vividly and were sensitive after the experiment as before as seen by their rapid reaction against minor sounds made during the observation. Then, it may be concluded from this experiment that a bright light of about 10000 lux never affects seriously this small nocturnal animal.

\section{Effect of Temperature on Behavior}

Two groups, each of ten animals, were subjected to a gradual temperature change from $3^{\circ}$ to $60^{\circ} \mathrm{C}$ and their behaviors were recorded. The group $\mathrm{A}$ had been kept at $8-12^{\circ} \mathrm{C}$ for a week and the group $\mathrm{B}$ at $30-31^{\circ} \mathrm{C}$ for a week and more before experiment. The temperature change was brought about in the method illustrated in Figure 3; a flask of $500 \mathrm{ml}$ containing ten animals was bathed in icy water in a vessel which was then heated slowly at the rate of 0.85 to $1.25^{\circ} \mathrm{C}$ per minute. The mouth of the flask was plugged with cotton to fix a thermometer. Behaviors of Tylos at respective temperatures are recorded in Figure 3.

Group A (acclimatized at $8-12^{\circ} \mathrm{C}$ ): The animals started very slow crawling at $3^{\circ} \mathrm{C}$ and became active and crawling normally one by one with the rising temperatures, till all were active at $11^{\circ} \mathrm{C}$. Their normal crawling was observed between 11 and $30^{\circ} \mathrm{C}$. At temperatures over $30^{\circ} \mathrm{C}$, their crawling speed became higher and higher with the temperatures and finally at $40^{\circ} \mathrm{C}$ turned on their back sometimes in a syncopic manner, soon got up to crawl rapidly, but turned again. As the temperature was raised further, the animals in the syncopic state increased and at last all the animals never got up again, thus they were completely killed at $46.7^{\circ} \mathrm{C}$.

Group B (kept at $30-31^{\circ} \mathrm{C}$ ): All the animals remained inactive at 3 to $10^{\circ} \mathrm{C}$. At $13.5^{\circ} \mathrm{C}$ only a single animal moved its antennae, at $15.8^{\circ} \mathrm{C}$ three animals were found active, moving their appendages or crawling, and at about $20^{\circ} \mathrm{C}$ a half of the animals crawled about normally. Then, the animals in normal behaviors increased as the temperature was raised gradually, though a single individual remained inactive in a rolled state throughout the experiment. The crawling speed became conspicuously high at $40^{\circ} \mathrm{C}$, almost all animals were fallen at $44.1^{\circ} \mathrm{C}$, all turned on their back at $45.6^{\circ} \mathrm{C}$, and were completely killed at $50.8^{\circ} \mathrm{C}$.

The temperature range for normal crawling was 10 to $30^{\circ} \mathrm{C}$ for animals of the Group A previously kept at $8-12^{\circ} \mathrm{C}$ and 20 to $35^{\circ} \mathrm{C}$ for those of the Group B kept at $30-31^{\circ} \mathrm{C}$. The first movement of the animal was seen at the temperature slightly below $3^{\circ} \mathrm{C}$ in the Group $\mathrm{A}$, but at $13.5^{\circ} \mathrm{C}$ in the Group B. The last animal was killed at $46.7^{\circ} \mathrm{C}$ in the Group $\mathrm{A}$, but at $50.8^{\circ} \mathrm{C}$ in the Group B. Though evidently acclimation was involved in the reaction of Tylos granulatus to the temperature, the temperature range for their normal activity was suggested to be 20 to $30^{\circ} \mathrm{C}$. 


\section{Effect of Higher Temperatures on Survival}

Further two experiments were made to see the effect of temperature on Tylos, by examining the survival time of animals at different higher temperatures. Ten animals were tested in a $500 \mathrm{ml}$ flask immersed to the middle of its height in a temperature-controlled water bath.

In the first experiment, the humidity inside the flask was not controlled, so that it should be rather low, because the experiment was carried out in December 1972 to January 1973, the season of lower humidities in Japan, on the one hand and the air inside the flask was heated, too, but without any supply of vapor on the other hand. Observations were made at intervals of less than two hours and the survival time was defined as the middle of two successive observations, when animals were
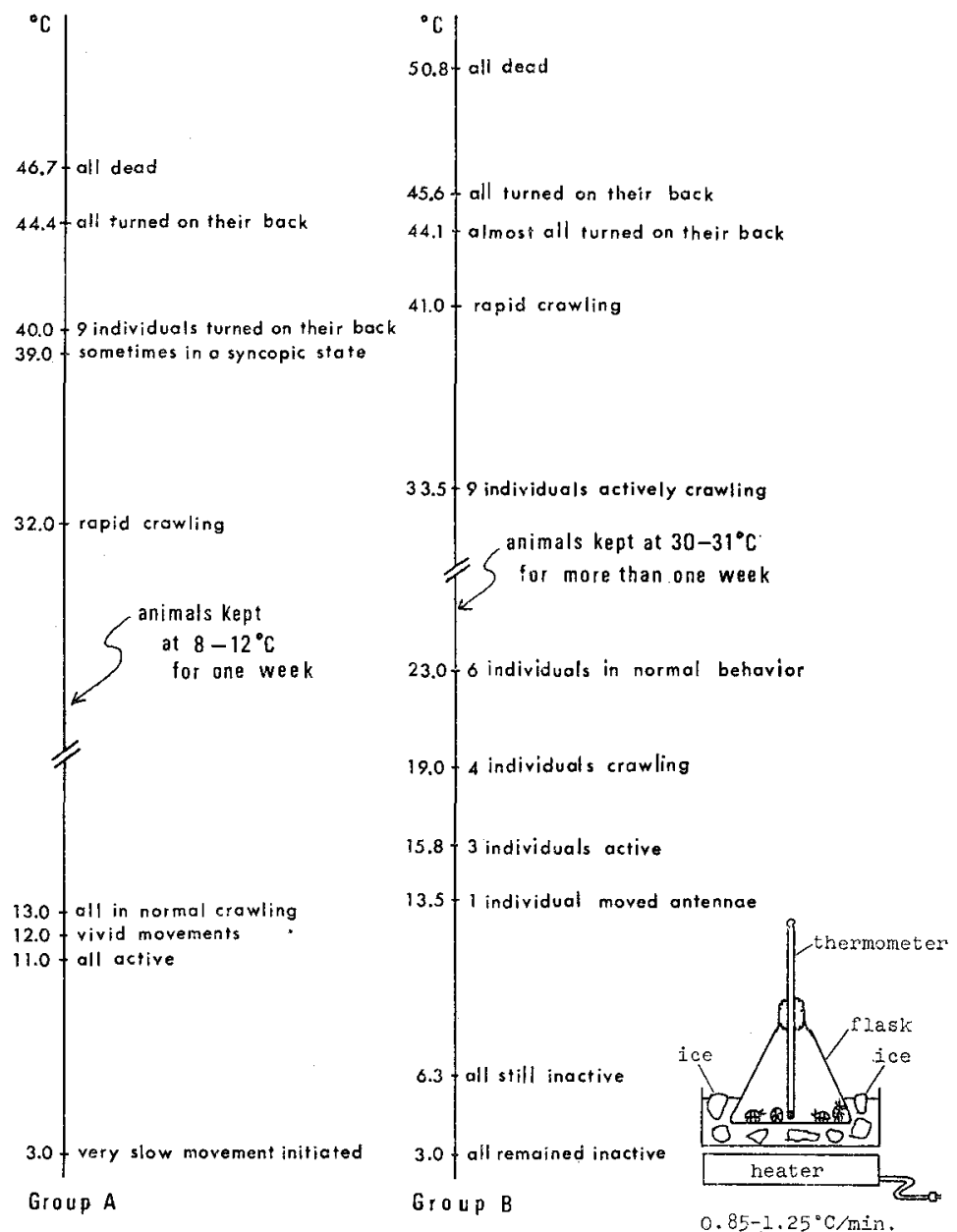

Fig. 3. Reaction of Tylos to the gradual rise of temperature from $3^{\circ}$ to $60^{\circ} \mathrm{C}$.

Two groups, each of ten animals, were observed; one (A) previously kept at $8-12^{\circ} \mathrm{C}$, while the other $(\mathrm{B})$ at $30-31^{\circ} \mathrm{C}$. 
found alive in the first, while killed in the last observation. The mean survival time and standard deviation at $34.7^{\circ} \mathrm{C}, 40.1^{\circ} \mathrm{C}, 44.4^{\circ} \mathrm{C}$ and $49.4^{\circ} \mathrm{C}$ are shown in a broken line in Fig. 4. Tylos could not survive more than 30 minutes at $49.7^{\circ} \mathrm{C}$, but 2.8 hours at $44.4^{\circ} \mathrm{G}, 6.1$ hours at $40.1^{\circ} \mathrm{G}$ and 12.8 hours at $34.7^{\circ} \mathrm{C}$. As the body weight of animals killed at even lower temperatures $\left(35-40^{\circ} \mathrm{C}\right)$ was significantly decreased, it was suggested that the death was caused not only by higher temperature itself but also by the loss of water.

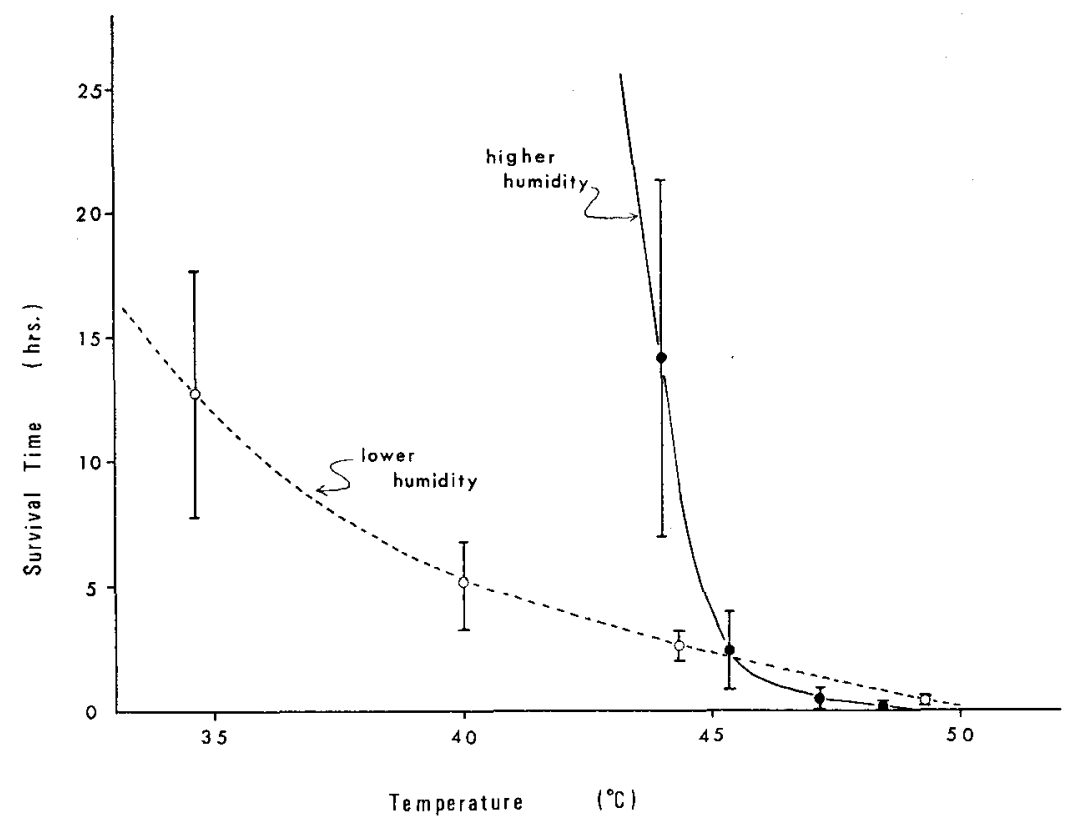

Fig. 4. Effect of higher temperatures on survival.

Ten animals were tested at each of different higher temperatures and the survival time was read. In one experiment (broken line), the humidity inside the flask holding animals was uncontrolled and therefore it was significantly lower, while in the other experiment (solid line) higher humidities were maintained. Standard deviations are given in solid vertical lines. In the highly humid condition, only one animal was killed by $26.5 \mathrm{hrs}$. of exposure at $39.7^{\circ} \mathrm{C}$, but by $51.6 \mathrm{hrs}$. exposure at $34.8^{\circ} \mathrm{C}$, while the rest survived the time of experiments, more than $44.4 \mathrm{hrs}$. and $100 \mathrm{hrs}$. respectiviely.

Therefore in the second experiment, some pieces of wet gauze was put on the flask bottom to supply enough vapor inside the flask. The survival time in the condition of higher humidities at $44.1^{\circ} \mathrm{C}, 45.4^{\circ} \mathrm{C}, 47.2^{\circ} \mathrm{C}$ and $48.5^{\circ} \mathrm{C}$ is shown in a solid line in Fig. 4. This time, Tylos survived longer at temperatures below $45^{\circ} \mathrm{C}$ : it survived 14.1 hours at $44.1^{\circ} \mathrm{C}$; this was longer than the survival time at $34.7^{\circ} \mathrm{C}$ in the preceding experiment. At $39.7^{\circ} \mathrm{C}$, one animal survived only 26.5 hours, but the other nine more than 44.4 hours. At $34.8^{\circ} \mathrm{C}$, one of ten was killed by 51.6 hours of exposure, but the other nine survived more than 100 hours.

The results obtained so far may be summarized as follows: this small animal living on the pebbly beach survives relatively longer in the moist air and the critical 
temperature is around $45^{\circ} \mathrm{G}$, therefore the animal will be killed in a short time at temperatures above this even in very humid condition.

\section{Selection of Sizes of Substratum Elements and Humid Conditions}

From the field observations (Fig. 1), it was found that the occurrence of Tylos was not correlated with the size of substratum elements. To confirm this again in the laboratory and at the same time to learn about the hygrotaxis of $T y l o s$, the following experiments were designed.

Ten animals were put in a round glass vessel that was $11 \mathrm{~cm}$ in diameter and $5 \mathrm{~cm}$ in height, and divided by a plate into two compartments respectively filled with different types of bottom elements, pebbles of 6-30 $\mathrm{mm}, 4-6 \mathrm{~mm}$ or sand of $0-2 \mathrm{~mm}$ in size and each dry or wet. The animals placed on the bottom surface in the vessel were left intact over a night and the animals hidden in respective compartments were counted next daytime. The results are shown in Table 6.

No clear selection of any sizes of substratum elements was observed when the comparison was made between different but both wet elements, as animals were found from either pebbles, gravels, or sand (Table 6, B). A similar result was obtained when different but both dry elements were compared (Table 6, A), though they seemed to avoid the substratum of dry sand. On the other hand, very clear trends were ob-

Table 6. Selection of sizes of substratum elements and humid conditions.

Ten animals were placed on the substratum of the vessel divided into two compartments respectively filled with elements of different sizes, both dry (A), both wet (B), or dry and wet $(\mathrm{C})$, left intact over a night, and animals in respective parts were counted next day. Experiment was repeated ( $I$ and II) in the condition A and $B$.

D: dry elements, $W$ : wet elements.

\begin{tabular}{|c|c|c|c|c|c|c|c|c|c|c|}
\hline Elements & & $\begin{array}{c}\text { Element } \\
\text { Size } \\
(\mathrm{mm})\end{array}$ & & $\begin{array}{l}\text { Number } \\
\text { of } \\
\text { Animals }\end{array}$ & $\begin{array}{c}\text { Element } \\
\text { Size } \\
(\mathrm{mm})\end{array}$ & & $\begin{array}{l}\text { Number } \\
\text { of } \\
\text { Animals }\end{array}$ & $\begin{array}{l}\text { Element } \\
\text { Size } \\
(\mathrm{mm})\end{array}$ & & $\begin{array}{l}\text { Number } \\
\text { of } \\
\text { Animals }\end{array}$ \\
\hline \multirow{4}{*}{ Dry (A) } & \multirow{2}{*}{ I } & $\int 0-2$ & $\mathrm{D}$ & $1 *$ & $\int 4-6$ & $\mathrm{D}$ & 2 & $\int 0-2$ & D & 2 \\
\hline & & 46 & $\mathrm{D}$ & 7 & $6-30$ & $\mathrm{D}$ & 8 & $6-30$ & $\mathrm{D}$ & 8 \\
\hline & \multirow{2}{*}{ II } & $\int 0-2$ & $\mathrm{D}$ & 0 & $\int 4-6$ & $\mathrm{D}$ & 8 & $\int 0-2$ & D & 0 \\
\hline & & $\{4-6$ & $\mathrm{D}$ & 10 & $6-30$ & D & 2 & $6-30$ & $\mathbf{D}$ & 10 \\
\hline \multirow{4}{*}{ Wet (B) } & \multirow[b]{2}{*}{ I } & $\int 0-2$ & W & 9 & $\int 4-6$ & W & 7 & $\int 0-2$ & W & 9 \\
\hline & & $\left\{\begin{array}{l}4-6 \\
-1\end{array}\right.$ & W & 1 & $\{6-30$ & W & 3 & $6-30$ & W & 1 \\
\hline & \multirow{2}{*}{ II } & $\int 0-2$ & W & 2 & $\int 4-6$ & W & 4 & $\int 0-2$ & W & 5 \\
\hline & & $\{4-6$ & W & 8 & $6-30$ & W & 6 & $6-30$ & W & 5 \\
\hline \multirow{6}{*}{ Dry and Wet (G) } & & $\int 0-2$ & W & 10 & $\int 4-6$ & W & 10 & $\int 6-30$ & W & 10 \\
\hline & & $0-2$ & D & 0 & $\{4-6$ & $\mathrm{D}$ & 0 & $\{6-30$ & $\mathrm{D}$ & 0 \\
\hline & & $\int 0-2$ & $\mathrm{D}$ & 0 & $\int 4-6$ & $\mathrm{D}$ & 0 & $\int 0-2$ & $\mathbf{D}$ & 0 \\
\hline & & $4-6$ & W & 10 & $6-30$ & W & 10 & $6-30$ & W & 10 \\
\hline & & $\int 0-2$ & W & 10 & $\int 4-6$ & W & 9 & $\int 0-2$ & W & 10 \\
\hline & & $\{4-6$ & $\mathrm{D}$ & 0 & $\{6-30$ & $D$ & 1 & $\{6-30$ & $\mathrm{D}$ & 0 \\
\hline
\end{tabular}

* Two individuals were found crawling on the substratum. 
served when dry and wet elements were compared regardless of their sizes (Table 6, C). Except for only a single individual found from the dry gravel of 6-30 $\mathrm{mm}$, all the animals tested prefered the substratum of wet elements to that of dry elements. Seemingly this agrees well with the observations in the field (Fig. 1). It can be concluded, therefore, that the humid or wet condition is much more important to these animals than the size of substratum elements and Tylos granulatus prefers decidedly the wet condition to the dried circumstance.

\section{Effect of Humidity on Survival}

In order to see the effect of humidity more closely, the survival of this species was checked in different relative humidities.

In respective experiments ten animals, 10 to $20 \mathrm{~mm}$ in body length, imprisoned in a glass vessel, $7 \mathrm{~cm}$ in diameter, $1.5 \mathrm{~cm}$ high and covered with a sheet of gauze, were maintained at $24 \pm 1.0^{\circ} \mathrm{C}$ in a container, the relative humidity in which was controlled to be at a fixed level with sulphuric acid, as seen in Fig. 5. Observations were made rather often in early stages of the experiment, at intervals of about 30 minutes, but later at intervals of 5-8 hours and the time when animals were killed was defined as the middle of two successive observations, an animal was alive in the first but killed

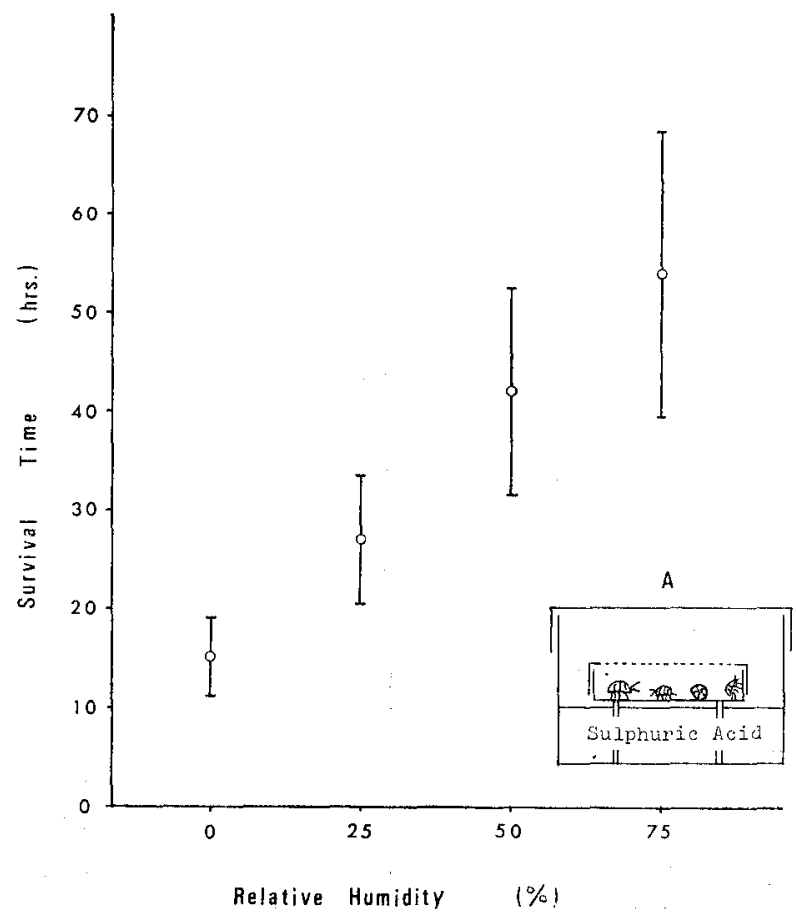

Fig. 5. Effect of humidity on survival of Tylos.

Animals, $10-20 \mathrm{~mm}$ in body length, were kept at different relative humidities controlled by using sulphuric acid (A) at $24 \pm 1{ }^{\circ} \mathrm{C}$. At the relative humidity of $100 \%$, one animal died 67 hours, another was eaten by others 92 hours after the initiation of the experiment, while the remaining eight survived more than 112 hours. 
in the last observation. The survival of Tylos granulatus at the relative humidity of $0,25,50$ and $75 \%$ is given in Fig. 5. The figure shows that the animals survived 15 hours at the relative humidity of $0 \%, 27$ hours at $25 \%, 42$ hours at $50 \%$ and 54 hours at $75 \%$. At the relative humidity of $100 \%$, one animal died 67 hours and another was found eaten by others 92 hours after the beginning of the experiment, but the remaining eight individuals survived more than 112 hours till the experiment was over.

From these experiments, it may be concluded that Tylos granulatus is remarkably weak to desiccation, surviving only 15 hours at most in the perfectly dry condition, but more than 100 hours in the saturated air at $24^{\circ} \mathrm{C}$.

7. Effect of Salinity on Survival

From the previous experiments, it was clear that Tylos prefered wet places and survived longer at higher humidities. Actually the habitat of Tylos may be sometimes washed by fresh water at rainfall, but sometimes by sea water in rough weather. Therefore, they have to be immersed rather frequently in water of different salinities.

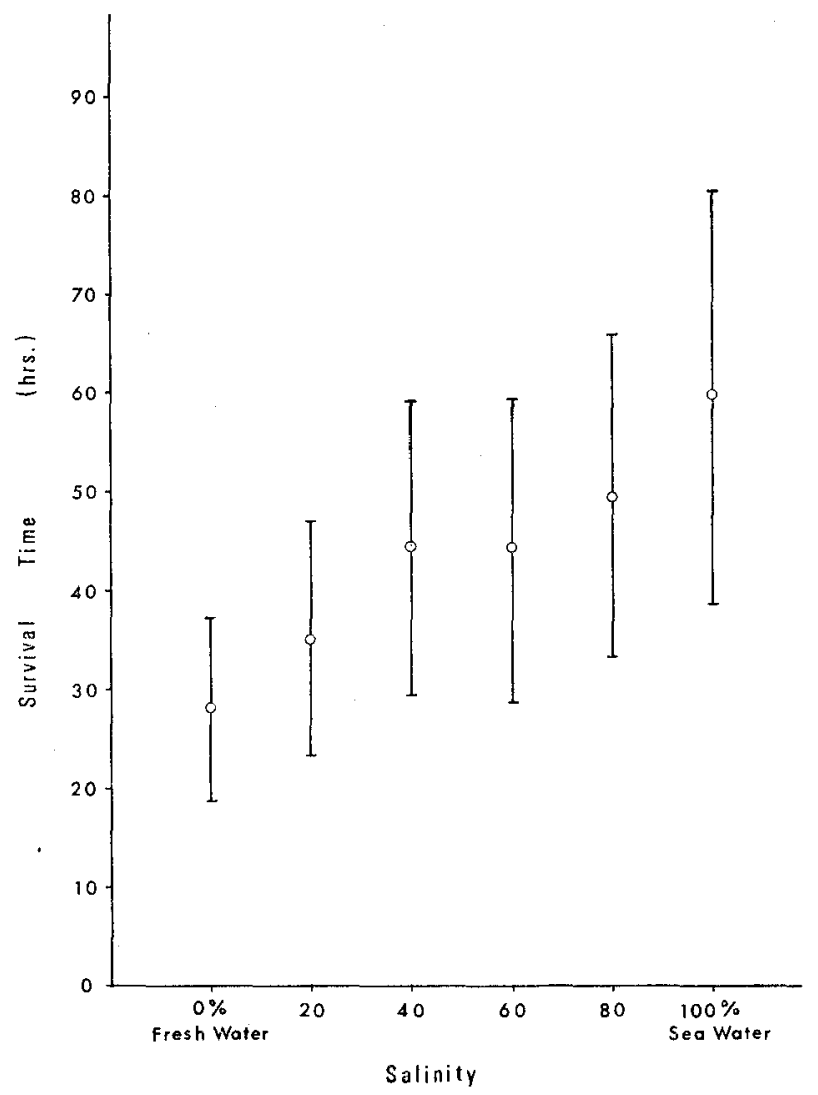

Fig. 6. Effect of dilution of sea water on survival of Tylos.

Survival of 10 animals, $10-20 \mathrm{~mm}$ in body length, was checked in the immersion in the water of different salinities at $20-21^{\circ} \mathrm{C}$. 
Thus the survival of this animal was checked at different salinities of immersion water.

Ten animals, 10-20 mm in body length, were immersed in a glass vessel, $11 \mathrm{~cm}$ high and $7 \mathrm{~cm}$ in diameter, into $250 \mathrm{ml}$ of water, the salinity of which was adjusted by mixing sea water and fresh water to provide a series of $0,20,40,60,80$ and $100 \%$ salinity of sea water with the density of $1.0250 \mathrm{~g} / \mathrm{cm}^{3}$. The temperature was maintained at 20 to $21^{\circ} \mathrm{C}$ throughout the experiments.

The results are shown in Fig. 6. In fresh water $0 \%$ solution of sea water, Tylos survived 28 hours. The more saline the solution was, the longer the animal survived in it, and in $100 \%$ of sea water the animals survived 61 hours. Thus, it was found that Tylos stood the immersion longer in the sea water than the fresh water, though it could not survive more than three days even in the sea water. This may be attributed to that the species is adapted to the respiration in the air, but not in the water. This may also explain its landward migration in a stormy weather. From the present experiments, the Japanese specimens seemed to stand the immersion in the sea water longer than the African specimens, as Kensley (1974) reported that the adults more than $20 \mathrm{~mm}$ in body length of the same species in Africa survived in the sea water only about 10 hours at $17^{\circ} \mathrm{G}$, though the juveniles less than $20 \mathrm{~mm} 10$ to 24 hours.

\section{Exposure of Tylos to the Daytime Condition}

The biological significance of the nocturnal habit of this animal may be learned by exposing the animal to the daytime conditions in its habitat and observing its behaviors.

Thus, 20 animals collected on the studied beach and respectively put in 20 glass bowls, $12.5 \mathrm{~cm}$ in diameter and $5.5 \mathrm{~cm}$ high, were placed around the center on the pebbly beach (Fig. 1) and exposed to the direct sunlight and ambient air. The animals were tested in two groups, Group A and Group B. In the former, a small amout of water was kept at the bottom of bowls each holding a single animal, while in the latter the bowls were not watered so that the animals in respective vessels were tested in quite dry conditions. The experiment was made on July 28, 1975 from $11: 20$ to $16: 00$, when it was fine, with a moderate breeze from the sea, the atmospheric temperature fluctuated from 34.5 to $38.0^{\circ} \mathrm{G}$ and the relative humidity from $35 \%$ to $46 \%$ at the site of experimentation.

Just after the experiment was set out, the animals crawled around on the bowl bottom and tried to climb up the bowl wall to get out, but in vain, in both groups. The animals in Group A, however, soon became quiet at the water edge on the bowl bottom, while the animals in Group B continued their restless efforts and fell into a desiccated condition about 15 minutes after the direct exposure to the sunlight, that was discerned by fading away of the color along the posterior edge of respective terga into white. This symptom appeared in some animals in Group A though somewhat late. The animals in Group B began to turn on their back 40 minutes after the exposure and then were killed one by one with the time. The survival time of each 
Table 7. Survival of Tylos in exposure to the daytime condition in the summer season on the studied pebbly beach.

The experiment was made on July 28, from $11: 20$ to $16: 00$, in the conditions of $34^{\circ}$ to $38^{\circ} \mathrm{C}$ and 35 to $46 \%$ of relative humidity. Animals were tested in watery state in Group A, while in drought in Group B. Survival time and decrease in body weight by water loss were checked.

\begin{tabular}{|c|c|c|c|c|c|}
\hline \multirow{2}{*}{ Animal Group } & \multirow{2}{*}{$\begin{array}{l}\text { Individual } \\
\text { Number }\end{array}$} & \multicolumn{2}{|c|}{ Body Weight } & \multirow{2}{*}{$\begin{array}{c}\text { Difference by } \\
\text { Water Loss } \\
\text { (to Body Weight) }\end{array}$} & \multirow[b]{2}{*}{ Survival Time } \\
\hline & & $\begin{array}{c}\text { Start of } \\
\text { Experiment }\end{array}$ & $\begin{array}{c}\text { End of } \\
\text { Experiment }\end{array}$ & & \\
\hline \multirow{11}{*}{$\begin{array}{c}\text { Group A } \\
\text { in Watery State }\end{array}$} & 1 & $0.56 \mathrm{~g}$ & $0.57 \mathrm{~g}$ & $+1.8 \%$ & more than $270 \mathrm{~min}$ \\
\hline & 2 & 0.47 & 0.49 & +4.3 & " \\
\hline & 3 & 0.49 & 0.48 & -2.0 & $"$ \\
\hline & 4 & 0.43 & 0.40 & -7.0 & " \\
\hline & 5 & 0.46 & 0.39 & -15.2 & " \\
\hline & 6 & 0.46 & 0.44 & -4.3 & " \\
\hline & 7 & 0.40 & 0.38 & -5.0 & " \\
\hline & 8 & 0.20 & 0.17 & -15.0 & $"$ \\
\hline & 9 & 0.31 & 0.30 & -3.2 & $"$ \\
\hline & 10 & 0.29 & 0.27 & -6.9 & $"$ \\
\hline & & & & $-5.3 \pm 6.3^{*}$ & more than 270 \\
\hline \multirow{11}{*}{$\begin{array}{l}\text { Group B } \\
\text { in Drought }\end{array}$} & 11 & 0.52 & 0.39 & -25.0 & 130 \\
\hline & 12 & 0.52 & 0.39 & -25.0 & 90 \\
\hline & 13 & 0.48 & 0.33 & -31.3 & 130 \\
\hline & 14 & 0.39 & 0.30 & -23.1 & 91 \\
\hline & 15 & 0.42 & 0.34 & -19.0 & 55 \\
\hline & 16 & 0.43 & 0.32 & -25.6 & 55 \\
\hline & 17 & 0.46 & 0.30 & -34.8 & 99 \\
\hline & 18 & 0.33 & 0.24 & -27.3 & 140 \\
\hline & 19 & 0.36 & 0.30 & -16.7 & 126 \\
\hline & 20 & 0.28 & 0.18 & -35.7 & 130 \\
\hline & & & & $-26.4 \pm 6.2^{*}$ & $105 \pm 30^{*}$ \\
\hline
\end{tabular}

* Mean and standard deviation

animal was shown in Table 7 . The animals survived only $105 \pm 30$ minutes in direct exposure to the sunlight in drought, but more than 270 minutes in exposure to the direct sunlight in watery state. The animals might survive much longer in the latter condition, though they looked not so vivid as before when the experiment was closed.

It is suggestible that the animals in Group B were killed by loss of the body water, because their body weight was much decreased by the experiment as seen in Table 7. The body weight was decreased by $26.4 \%$ in group B, but only $5.3 \%$ in Group A. This experiment shows the importance of water very clearly. In their natural habitat, the direct sunlight or the daytime temperature on the pebbly beach would never affect fatally on this nocturnal animal, because the animals tested in watery state survived actually a significantly long time of experiment under the strongest solar radiation and at the highest atmospheric temperature. 
9. Conclusion of Physiological Properties of Tylos

In the series of experiments, effects of the light, temperature, humidity and immersion in the water on the behavior and survival of Tylos were examined. Continuous exposure to the bright light of ca. $10000 \mathrm{lux}$ as well as to the direct sunlight seemed not so seriously effective on the survival of this animal. As Tylos showed a positive phototaxis to the light of lower intensities, it is suggested that such light of lower intensities was not harmful to it. In very humid condition, Tylos stood relatively higher temperatures below $45^{\circ} \mathrm{C}$, but in drought the survival time of the animal remarkably shortened, less than 2 hours at $34-38^{\circ} \mathrm{C}$ in nature and about 15 hours at $24^{\circ} \mathrm{C}$ in the laboratory. Tylos seemed to avoid immersion in the water, either the sea water or fresh water; it was killed in 30 to 60 hours by immersion.

Thus, it may be concluded as follows: Tylos can survive a longer time in the moist condition probably regardless of illumination, if the temperature remains below $45^{\circ} \mathrm{C}$. Immersion in the water or exposure to the drought condition is unfavorable to Tylos. This nature is seemingly limiting the distribution of the animal to the supratidal zone, but not far from the water edge, and also keeping the animal nocturnal to prevent the loss of water mainly through the respiratory organ not yet adapted perfectly to the terrestrial life.

\section{Factors Controlling the Activity of Tylos}

The animals living on or near the earth surface are inevitably subjected to constant fluctuations of some physical and biological factors. Of these factors, the light, temperature and humidity are seemingly related closely with the activity of Tylos granulatus, therefore the effect of cycles of the light, temperature, humidity and combinations of these on the activity of Tylos granulatus was examined by the following experiments.

The animals collected from the habitat were divided into some groups of ten animals and these groups were kept in respective boxes of the following structure to be subjected to respective programed environmental cycles; the box (see Fig. 17) was composed of a hiding-space $(8 \mathrm{~cm} \times 3 \mathrm{~cm}$ and $5 \mathrm{~cm}$ deep $)$ filled with pebbles and an open "playground" $(8 \mathrm{~cm} \times 8 \mathrm{~cm})$ that was provided at the center with a large hole $(5 \mathrm{~cm}$ in diameter stretched with a net, through which the ground was communicated with an underlying humidity controlling chamber watered or holding some desiccating agents. The activity of Tylos was shown by the number of animals appeared on the surface of pebbles and in the "playground", that was confirmed on the photographs (an example given in Fig. 18) taken automatically every hour by Strobo, so that the animals were exposed to the flash light of $1 / 3000$ second every hour throughout all the experiments. The temperature in respective boxes was made constant by placing some boxes togather in larger temperature controlled boxes $(14.5 \mathrm{~cm} \times 37 \mathrm{~cm}$ and $21 \mathrm{~cm}$ deep) and the illumination was made with a fluorescent lamp of 750-1100 lux at the site of "playground" and switched on and off auto- 
matically. The dark phase meant the complete darkness or an illuminated state by dim light of ca. 1 lux by a pilot lamp. The light cycle was maintained simply by automatic switchover of a fluorescent lamp, while the temperature cycle was made by moving the test boxes between the different temperature controlling boxes set differently and the humidity cycle was brought about by changing the element inside the humidity controlling chamber under the "playground". Some animals died in the course of experiments, especially often in drought, and were recorded as inactive, because such dead animals were sometimes hidden among the pebbles till the end of experiments. Therefore, the graphs in Figs. 7-14 do not always express the ratio of the active animals to all the living animals but merely the number of active individuals of the ten animals ever kept in respective test boxes.

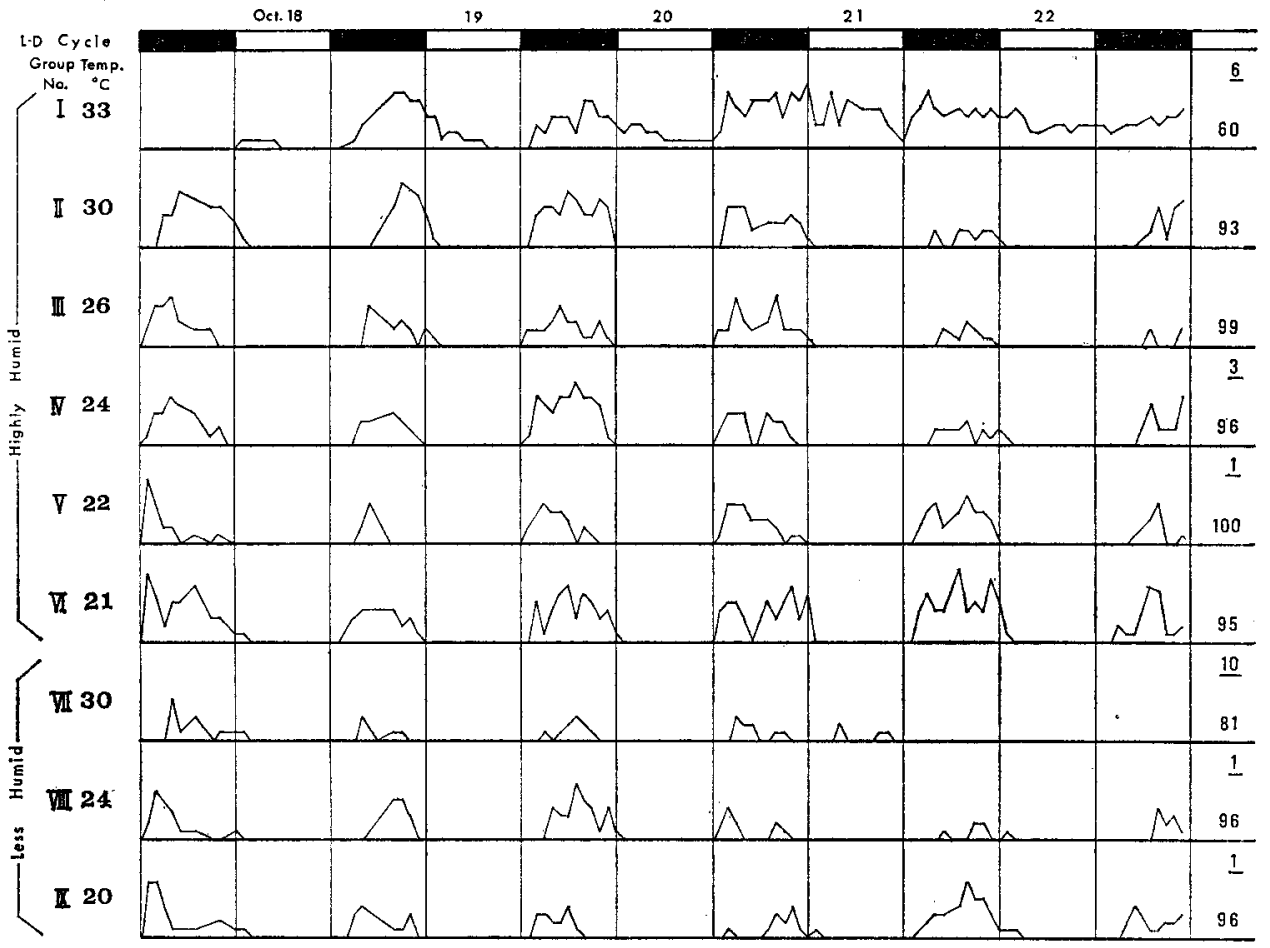

Fig. 7. The activity of Tylos in relation to the light cycle.

The animals collected on the beach on October 17 were subjected to the cycle of 12-hour light $(6: 00-18: 00$, shown by white zone at the top) and 12-hour dark (18:00-6:00, shown by black zone) after the evening of that day.

Groups I, II, III, IV, V and VI were kept at $33^{\circ}, 30^{\circ}, 26^{\circ}, 24^{\circ}, 22^{\circ}$ and $21^{\circ} \mathrm{C}$ respectively in the highly humid condition, while Groups VII, VIII and IX at $30^{\circ}, 24^{\circ}$ and $20^{\circ} \mathrm{C}$ respectively in the less humid condition.

The ordinate: numbers of animals appeared on the pebble surface of the hiding space and in the "playground" in respective boxes, in each ten animals were released.

Figures at the right end indicate at the bottom the rate of activity in the dark phase and at the top the number of individuals killed in the experiment (underlined, no indication when all animals survived the time of experiment). 


\section{Light Gycle (Fig. 7)}

The most dominant factor controlling the circadian rhythm of various organisms has been generally belived to be the cycle of the light. This may be natural, for the cycle of the light is the most regular one throughout all kinds of periodic variations of any environmental factors in nature. Therefore, the activity of Tylos granulatus was observed firstly in relation to the light cycle.

The animals collected on the beach on October 17, 1973 were divided into nine groups which were then imprisoned in respective boxes at 17:30 and subjected to an alternation of 12-hour light (6:00-18:00) and 12-hour dark (18:00-6:00) at different temperatures in the range from 20 to $33^{\circ} \mathrm{C}$ and at higher or lower humidities; Groups I, II, III, IV, V and VI were tested at $33^{\circ}, 30^{\circ}, 26^{\circ}, 24^{\circ}, 22^{\circ}$ and $21^{\circ} \mathrm{C}$ respectively in the highly humid condition, while Groups VII, VIII and IX at $30^{\circ}, 24^{\circ}$ and $20^{\circ} \mathrm{C}$ respectively in the less humid condition (Fig. 7).

As illustrated in Fig. 7, the activity of Tylos granulatus was limited to the dark phase regardless of humidity and temperature except for the animals of Group I kept at $33^{\circ} \mathrm{C}$, which became somewhat active even in the light phase. Thus, the temperature as higher as $33^{\circ} \mathrm{C}$ seemed too high for the animals collected in the field in autumn to maintain a regular nocturnal rhythm; six of ten animals were killed in this experiment. However, the mortality was highest in the Group VII kept at $30^{\circ} \mathrm{C}$ in drought, in which no animal survived the time of experiment, presumably because of desiccation at a higher temperature.

From these results, it was learned that the normal activity of Tylos granulatus was observable limitedly in the dark phase at temperatures below $30^{\circ} \mathrm{C}$.

\section{Constant Dim Light (Fig. 8)}

In order to see whether the nocturnal behavior of Tylos is endogenous or not, the activity of animals collected on the beach on October 24 was recorded under a continuous dim light of 1 lux. The animals were divided into 6 groups of ten individuals and Groups I-III were tested respectively at $30^{\circ}, 25^{\circ}$ and $20^{\circ} \mathrm{C}$ in the highly humid state, while Groups IV-VI respectively at the same temperatures but in less humid condition.

In the continuous dim light, animals showed a periodicity of about 24 hours even at different temperatures (Fig. 8). In the highly humid condition, however, the activity seemed to be amplified and some animals remained in the "playground", sometimes still, throughout 24 hours as seen in Groups II and III. On the contrary, in the dried condition, the activity was somewhat suppressed and the activity disappeared in the later part of the experiment in Groups IV and V; this was evidently attributed to the death of all the animals caused by desiccation promoted at higher temperatures. In the other groups almost all animals survived the time of whole observations.

From this experiment, it may be concluded that the activity rhythm of Tylos granulatus is endogenous, as the rhythm persisted steadily in the constant dim light without any fluctuation at different temperatures and humidities, and that the period 


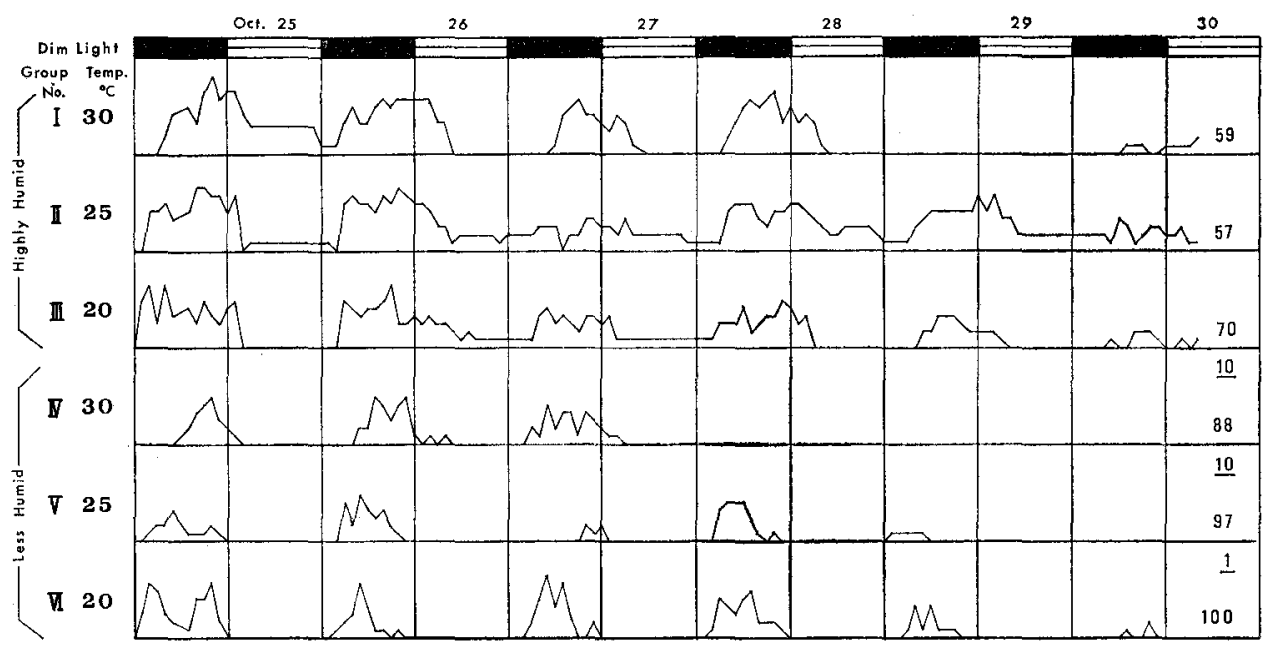

Fig. 8. Activity of Tylos under the continuous dim light of about 1 lux.

The night time in nature $(18: 00-6: 00)$ is shown by black zone at the top, while the daytime $(6: 00-18: 00)$ by striped zone at the top.

Figures at the right end indicate at the bottom the rate of the activity in the night time in nature (18:00-6:00) and show at the top the number of individuals killed in the experiment (underlined).

is about 24 hours, temperature-compensated at least in the range of $20^{\circ}$ to $30^{\circ} \mathrm{C}$, and the periodicity can be maintained as long as 6 days in the continuous dim light in the highly humid condition.

The experiment under the continuous light was abbreviated, because the aboveexperiment under the dim light was sufficient to show that the activity rhythm of Tylos is endogenous.

\section{Reversed Light Cycle (Fig. 9)}

It was found that the activity rhythm of Tylos itself was endogenous. However, it remained still unknown whether the activity rhythm (Fig. 7) observed under the light cycle of 12-hour light (6:00-18:00) and 12-hour dark (18:00-6:00) coordinated with the natural light cycle was due to the persistent rhythm already entrained in nature before the animals were collected, or simply due to the alternation of light and dark. In order to clarify this point, the activity of Tylos was recorded in the light cycle reversal to the natural cycle.

Three groups, each of ten animals, were subjected for first 2 days to the alternation of 12-hour light (6:00-18:00) and 12-hour dark (18:00-6:00) and then to the reversed cycle for 9 days by extending the light phase of the second day to 24 hours, respectively at $20^{\circ}, 25^{\circ}$ and $30^{\circ} \mathrm{C}$ in the highly humid condition (Fig. 9).

In the first tow days, the activity was limited to the dark phase. In the light phase of the first day of the reversed cycle, followed the light phase of the second day, the activity was suppressed and the same even in the dark phase of the same day. However, the behavior was soon adapted to the reversed light cycle, though a slight activity was seen in some light phases. It seemed that the perfect synchronization 

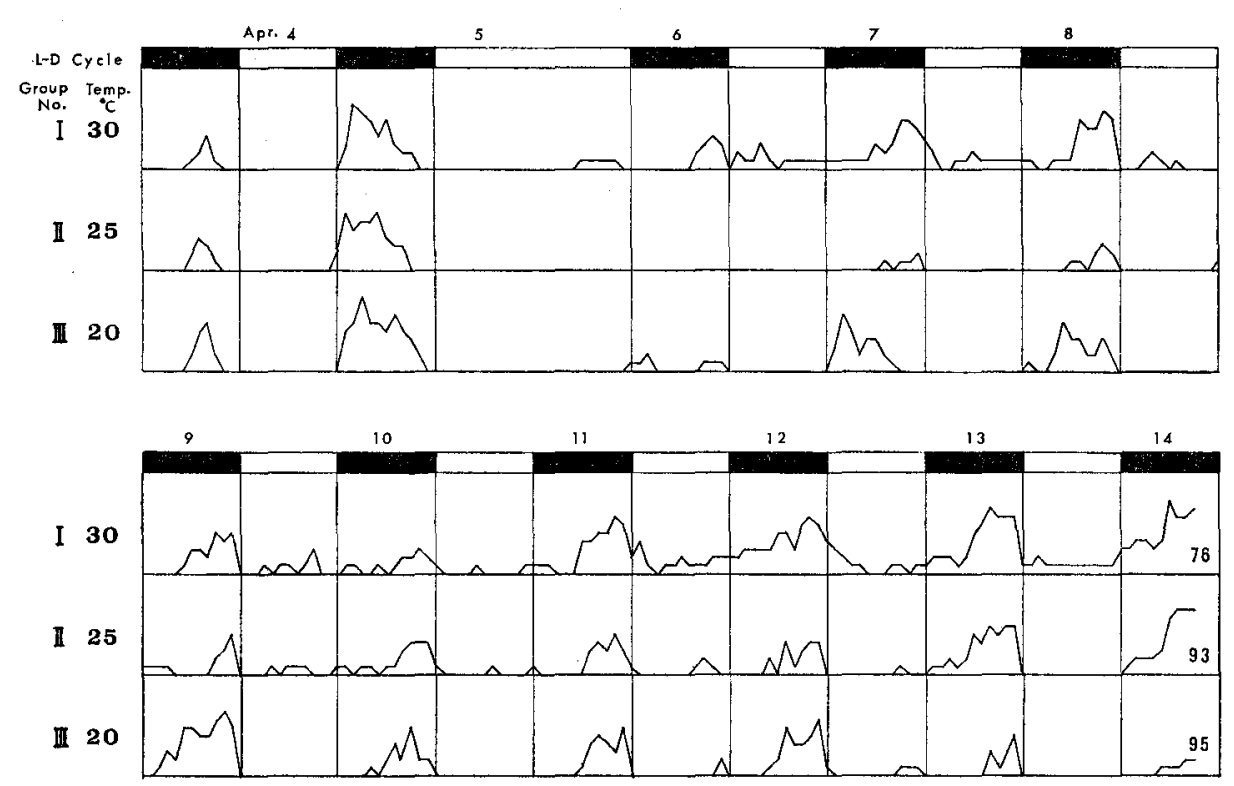

Fig. 9. Activity of Tylos under the reversed light cycle.

The natural cycle of 12-hour light from 6:00 to 18:00 and 12-hour dark from 18:00 to 6:00 was reversed on April 5, by extending the light phase to 24 hours, to the cycle of 12-hour light from 18:00 to 6:00 and 12-hour dark from 6:00 to 18:00. The humidity was maintained at higher levels in all groups.

Figures at the right end indicate the rate of the activity in the dark phase in the reversed light cycle.

would require more than 9 days. Anyhow, as the main activity rhythm was easily reversed by reversal of the light cycle, it is obvious that the light cycle itself is controlling the activity rhythm of Tylos granulatus.

\section{Temperature Cycle (Fig. 10)}

Six groups of ten animals were subjected to a regular cycle of 12-hour higher and 12-hour lower temperatures in the highly humid condition and under a continuous dim light. The experiment was started at 18:00 on October 30. The temperature cycle was brought about by moving the test boxes holding the animals between the larger temperature controlled containers set at different temperatures. Thus, Groups I and IV were subjected to the alternation of $25^{\circ}$ and $30^{\circ} \mathrm{C}$, Groups II and V $20^{\circ}$ and $25^{\circ} \mathrm{C}$, and Groups III and VI to the alternation of $20^{\circ}$ and $30^{\circ} \mathrm{C}$; Groups I, II and III were exposed to the higher temperature from 10:00 to 22:00 and to the lower temperature from 22:00 to 10:00, while the temperature cycle was reversed for Groups IV, V and VI. In group III, eight animals escaped from the box at 6:00 on October 31, five were captured and returned into the box at 8:00 on November 1, but the remaining three were lost. Only five individuals survived the time of experiment in Group III, though in the other groups, no one died during the experiment.

In the alternation of $30^{\circ}$ and $25^{\circ} \mathrm{C}$, in which the phase of lower temperature 


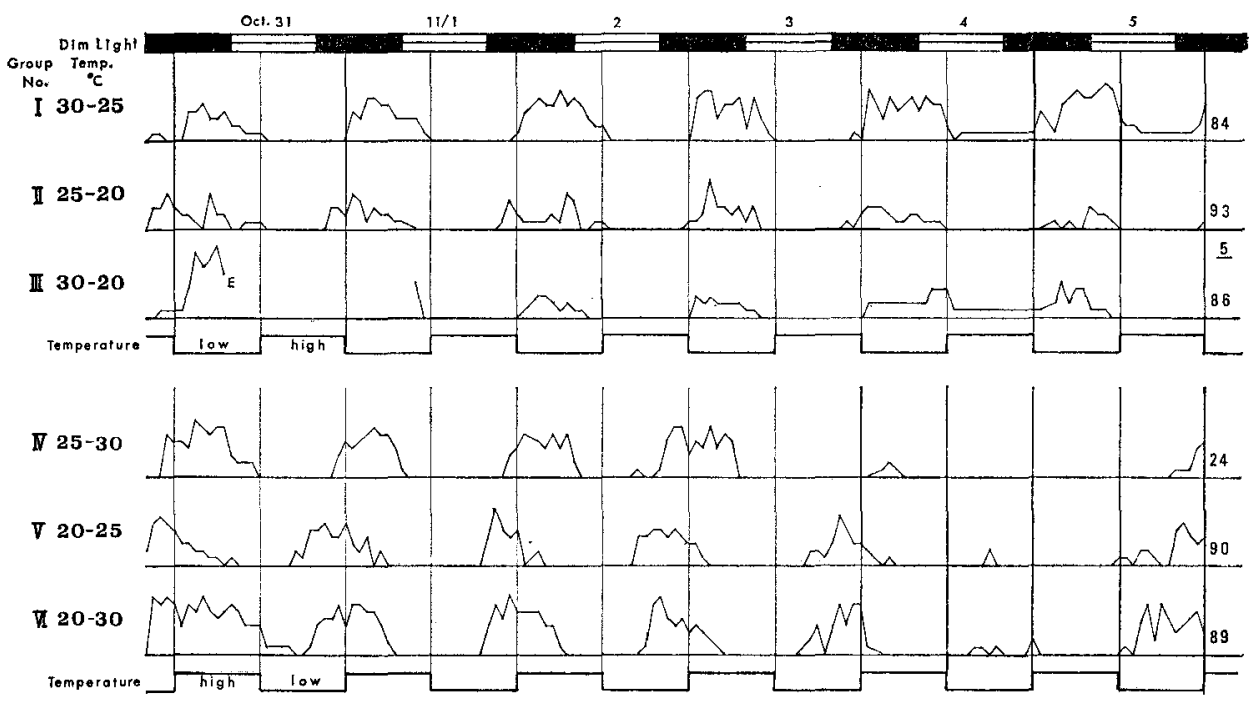

Fig. 10. Activity of Tylos under the temperature cycle.

The animals were exposed to the alternation of $30^{\circ}$ and $25^{\circ} \mathrm{C}$ (Groups I and IV), $25^{\circ}$ and $20^{\circ} \mathrm{C}$ (Groups II and V) or $30^{\circ}$ and $20^{\circ} \mathrm{C}$ (Groups III and VI) in the highly humid condition. Figures at the right end indicate at the bottom the rate of activity in the lower temperature in the last 3 days of the experiment and at the top the number of individuals killed in the experiment.

In Group III, eight animals escaped at 6:00 on October $31(\mathrm{E})$, but five of them were returned to the test box next morning at 8:00.

started about 4 hous later than the natural night phase (Group I), the animals were much more active in the lower temperature. The rate of the activity in the lower temperature phase was calculated with using the data from the last 3 days of the experiment in order to eliminate phase shifting period probably lying in the first 3 days of the experiment. By such method, the rate was shown to be $84 \%$ in Group I, while in the reversed cycle of the same temperatures (Group IV), it was much less and only $24 \%$. Thus, the endogenous rhythm of Tylos was never entrained at least in a week to the temperature cycle between $30^{\circ}$ and $25^{\circ} \mathrm{C}$. In the alternation of $25^{\circ}$ and $20^{\circ} \mathrm{C}$, the activity rhythm was seemingly entrained to the temperature cycle both in the normal (lower temperature roughly in the natural night phase) and reversed phases, as the rate of the activity in the lower temperature was $93 \%$ in the Group II (normal) and 90\% in the Group V (reversed). The same was suggested when the animals were subjected to the alternation of $20^{\circ}$ and $30^{\circ} \mathrm{C}$, as the activity seemed synchronized with the temperature cycle; the rate of the activity in the lower temperature was $86 \%$ in the Group III (normal), while $89 \%$ in the Group VI (reversed).

From this experiment, it may be concluded that the activity rhythm of $T_{y}$ los granulatus can be entrained to the alternation of $25^{\circ}$ and $20^{\circ} \mathrm{C}$ or $30^{\circ}$ and $20^{\circ} \mathrm{C}$, with the higher activity in the lower temperature.

5. Humidity Cycle (Fig. 11)

To see the effect of the humidity cycle on the activity of Tylos granulatus, six 


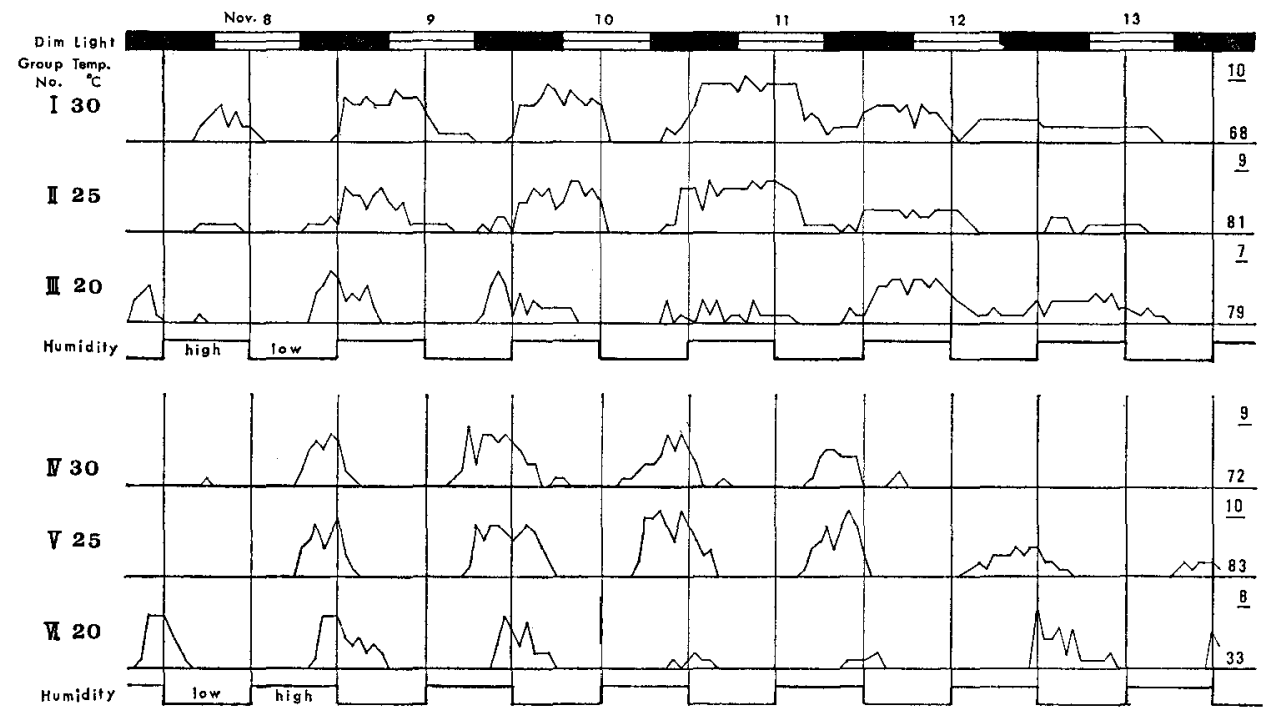

Fig. 11. Activity of Tylos under the humidity cycle.

The animals were exposed to the higher humidity from 23:00 to 11:00 (Groups I, II and III) or from 11:00 to 23:00 (Groups IV, V and VI).

Figures at the right end indicate at the bottom the rate of activity in higher humidity in the last 3 days of the experiment and at the top the number of individuals killed in the experiment.

groups, each of ten animals, were subjected to the alternation of drought and saturation under the constant dim light and at $30^{\circ} \mathrm{C}$ (Groups I and IV), $25^{\circ} \mathrm{C}$ (Groups II and V) or at $20^{\circ} \mathrm{C}$ (Groups III and VI). The animals were collected on the beach on November 7 and put in the test boxes at 17:30, when the experiment started. The highly humid (saturated) phase was maintained from 23:00 to 11:00 in Groups I, II and III, started about 5 hours later than the natural night phase, while reversedly from 11:00 to 23:00 in Groups IV, V and VI. Many animals were killed in this experiment probably by desiccation; ten animals were killed in Groups I and V, nine in Groups II and IV, eight in Group VI, and seven in Group III. Some dying animals appeared on the floor surface and remained there motionless for a long time; even these animals were recorded as active.

At higher temperatures, the activity of the animal was synchronized very soon with the highly humid phase; the rate of the activity in saturation calculated with using the data from the last 3 days of the experiment was $68 \%$ in Group I but $72 \%$ in Group IV at $30^{\circ} \mathrm{C}$ and $81 \%$ in Group II but $83 \%$ in Group V at $25^{\circ} \mathrm{C}$. However, the activity rhythm was not synchronized with the humidity cycle at $20^{\circ} \mathrm{C}$ within the experiment. In Groups III and VI, the activity rhythm coincided with the natural light cycle, the rate of the activity in the highly humid phase was $79 \%$ and $33 \%$ in Groups III and VI respectively.

From this experiment it may be concluded that the activity rhythm of Tylos granulatus was easily controlled by the fluctuation of humidity in the environments at higher temperature as $25^{\circ}$ and $30^{\circ} \mathrm{C}$, but not at $20^{\circ} \mathrm{C}$, with the shift of the active 
phase to the highly himid phase.

\section{Light-Temperature Cycle (Fig. 12)}

It was found in the previous experiments that the cycles of the light, temperature and humidity can each control the activity rhythm of Tylos at least to some extent. Then next, the combined effect of the light cycle and the temperature cycle (lighttemperature cycle) on the activity rhythm was checked in 6 groups of the animals in the following conditions, the dark phase coordinated with the lower temperature in three groups (Groups I, II and III), but with the higher temperature in the other groups (Groups IV, V and VI). The animals were exposed to the alternation of $25^{\circ}$ and $30^{\circ} \mathrm{C}$ in Groups I and IV, $20^{\circ}$ and $25^{\circ} \mathrm{C}$ in Groups II and V, while $20^{\circ}$ and $30^{\circ} \mathrm{C}$ in Groups III and VI. The light phase extended from 23:00 to 11:00 in all groups and the dark phase represented by the illumination with a dim light was maintained from 11:00 to $23: 00$, while the humidity remained high throughout the experiment. The experiment was started on Dec. 8, but actual recording was set on Dec. 10. Only a single animal was killed in Group $\mathrm{V}$ in the experiment.

When the cycles of light and temperature were given coordinately with each other in the condition of the dark phase joined with lower temperature, the activity appeared in the dark-cool phase at the rate of $99 \%$ in Group I, 100\% in Group II and $97 \%$ in Group III. On the other hand, the activity rhythm was not so clear in the condition of the dark phase joined with higher temperature, though in the

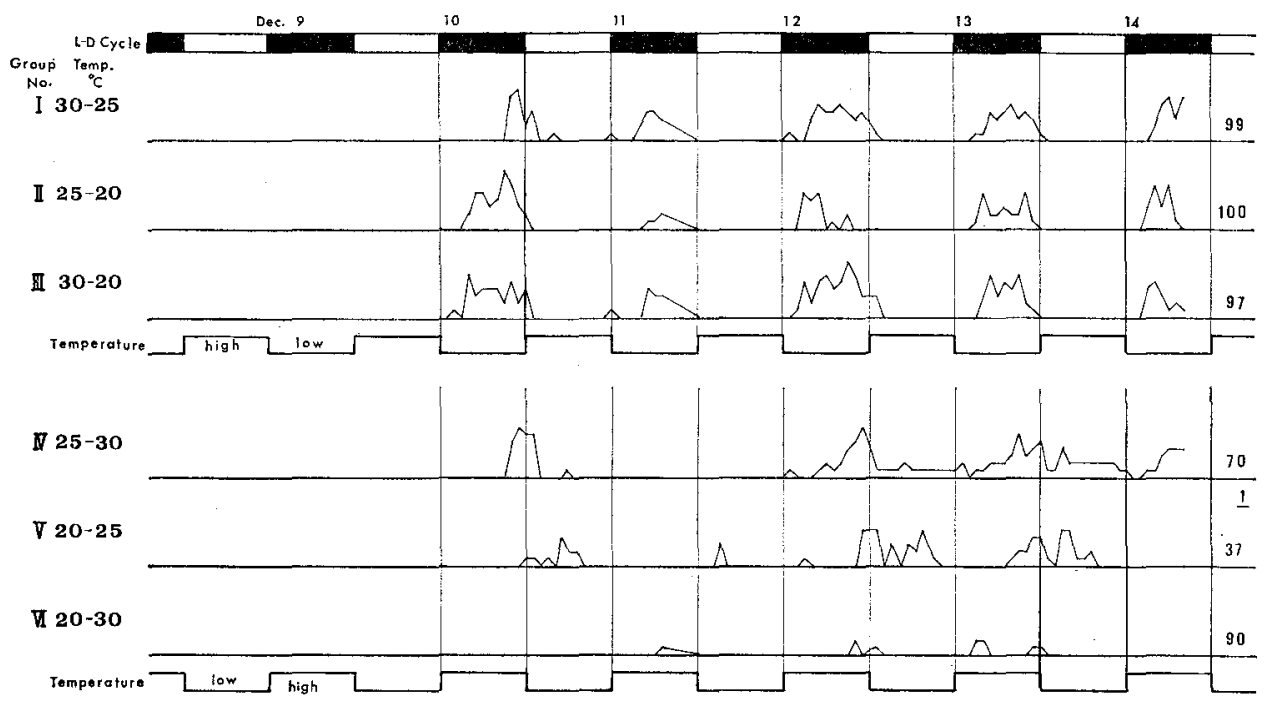

Fig. 12. Activity of Tylos under the light-temperature cycle.

The animals were exposed to the cycles of light and temperature coordinated with each other. The dark phase, from 11:00 to 23:00, was combined with the phase of lower temperature in Groups I, II and III, while with the higher temperature in Groups IV, V and VI. The experiment was started on Dec. 8, but actual recording on Dec. 10.

Figures at the right end indicate at the bottom the rate of the activity in the dark phase in the last 3 days of the experiment, and at the top the number of individuals killed in the experiment. 
temperature cycle of $25^{\circ}$ and $30^{\circ} \mathrm{C}$ (Group IV) or $20^{\circ}$ and $30^{\circ} \mathrm{C}$ (Group VI) the activity in the dark phase seemed more prominent, in spite of the higher temperature, respectively $70 \%$ and $90 \%$ in the rate. The light cycle seemingly predominated over the temperature cycle in these groups. However, the case seemed to differ markedly when the animals were subjected to the temperature cycle of $20^{\circ}$ and $25^{\circ} \mathrm{C}$ in the condition of the lower temperature combined with the light phase; the rate of activity in the dark phase was only $37 \%$.

From these results, it may be concluded that the activity rhythm of Tylos can be strongly synchronined with the light-temperature cycle, when the dark phase is joined with the phase of lower temperature. When the two cycles were given in the condition of the dark phase combined with the higher temperature, the activity was seemingly affected to some extent by the light cycle at the temperature alternation of $30^{\circ}$ and $25^{\circ} \mathrm{C}$ and $30^{\circ}$ and $20^{\circ} \mathrm{C}$, but it was under the control of the temperature cycle at the alternation of $25^{\circ}$ and $20^{\circ} \mathrm{C}$.

\section{Light-Humidity Cycle (Fig. 13)}

The activity of Tylos was recorded under the cycles of light and humidity (lighthumidity cycle) coordinated with each other. The light cycle composed of 12-hour light (23:00-11:00) and 12-hour dim light (dark) phases (11:00-23:00) was coordinated with the humidity cycle as the highly humid phase was set in the time from 11:00 to 23:00 (in the dark phase) in Groups I, II and III, or from 23:00 to 11:00

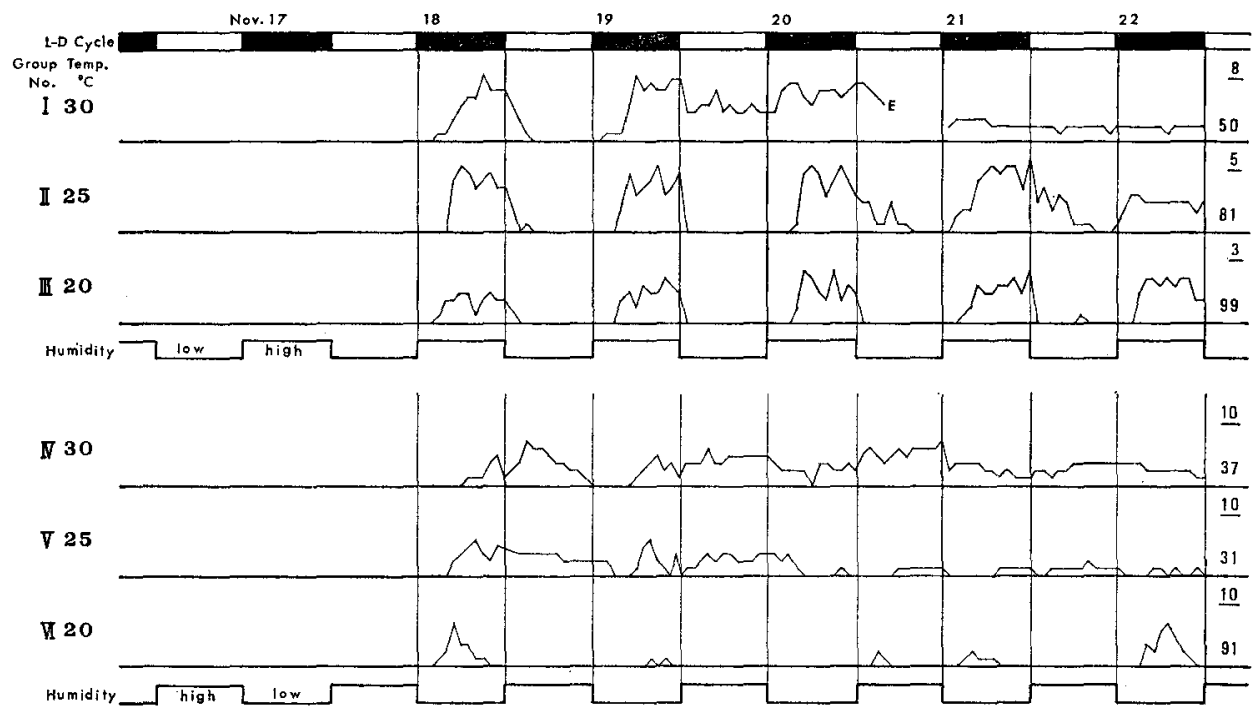

Fig. 13. Activity of Tylos under the light-humidity cycle.

The animals were exposed to the cycles of light and humidity coordinated with each other. The dark phase from 11:00 to 23:00 was combined with the highly humid phase in Groups I, II and III, but with less humid phase in Groups IV, V and VI. The experiment was started on Nov. 16, but actual recording on Nov. 18.

Figures at the right end indicate at the bottom the rate of activity in the dark phase in the last 3 days of the experiment and at the top the number of individuals killed in the experiment. 
(in the light phase) in Groups IV, V and VI. The experiment was started on November 16 , at $30^{\circ} \mathrm{C}$ in Groups I and IV, at $25^{\circ} \mathrm{C}$ in Groups II and V, and at $20^{\circ} \mathrm{C}$ in Groups III and VI, although recording was set out on Nov. 18. Many animals were killed in this experiment, too; 8, 5 and 3 animals in Groups I, II and III, respectively, and all 10 animals in Groups IV, V and VI.

In Group I, the activity rhythm was seen from November 18 to 19 but thereafter became obscure, 4 animals escaped from the box on November 21 . The rate of the activity in the dark-highly humid phase was only $50 \%$ in Group I, this seemed too low as compared with the rates in the dark phase of simple light cycle (Fig. 7) and the highly humid phase of simple humidity cycle (Fig. 11); probably the temperature of $30^{\circ} \mathrm{C}$ might be unusually high for the animals that had been acclimatized to lower temperatures in November. In Groups II and III, a clear rhythm with the active phase in the dark-highly humid phase was maintained throughout the experiment and the rate of the activity in this phase was $81 \%$ and $99 \%$ in Groups II and III respectively. The activity rhythm was relatively irregular when the two cycles were given in the condition of the dark phase combined with the phase of lower himidity, and the rate of the activity in the dark-less humid phase was $37 \%, 31 \%$ and $91 \%$ in Groups IV, V and VI kept at $30^{\circ}, 25^{\circ}$ and $20^{\circ} \mathrm{C}$ respectively. Thus, the activity was suppressed by the lower humidity even in the dark phase at higher temperature, while at lower temperature it was induced by the dark phase even at lower humidity. This may be attributed to the evaporation raised at higher temperatures.

From this experiment it is deducible that the activity rhythm of Tylos can be synchronized with the light-humidity cycle when the dark phase is combined with the highly humid phase. However, when the dark phase is joined with the phase of lower himidity, the activity rhythm tends to follow the himidity cycle at higher temperature but the light cycle at lower temperature.

\section{Temperature-Humidity Cycle (Fig. 14)}

The activity of Tylos was recorded under the temperature-humidity cycle in the continuous dim light. The lower temperature was coordinated with the highly humid phase in Groups I, II and III, while with the less humid phase in Groups IV, V and VI, at the alternation of $30^{\circ}$ and $25^{\circ} \mathrm{C}$ in Groups $\mathrm{I}$ and $\mathrm{IV}, 25^{\circ}$ and $20^{\circ} \mathrm{C}$ in Groups II and V, and $20^{\circ}$ and $30^{\circ} \mathrm{C}$ in Groups III and VI. The experiment was started on March 21, 1975. The number of animals killed in the experimental was 9 in Groups III and V, 8 in Groups I and IV, and 7 in Group VI.

The activity rhythm was not so clear in Group I, because the activity was seen in both phases of higher and lower temperatures and the rate of the activity in lower temperature was only $60 \%$. In Group II, however, the rhythm was rather clear and the activity was limited to the phase of lower temperature. In Group III, the activity of animals was seen continuously, therefore the rhythm was obscure, the rate of the activity in the phase of lower temperature was only $52 \%$. In Group IV, the activity was seen at the time of temperature drop but not restricted to either of the phases of higher or lower temperatures. In Group V, the animals escaped from the box three 


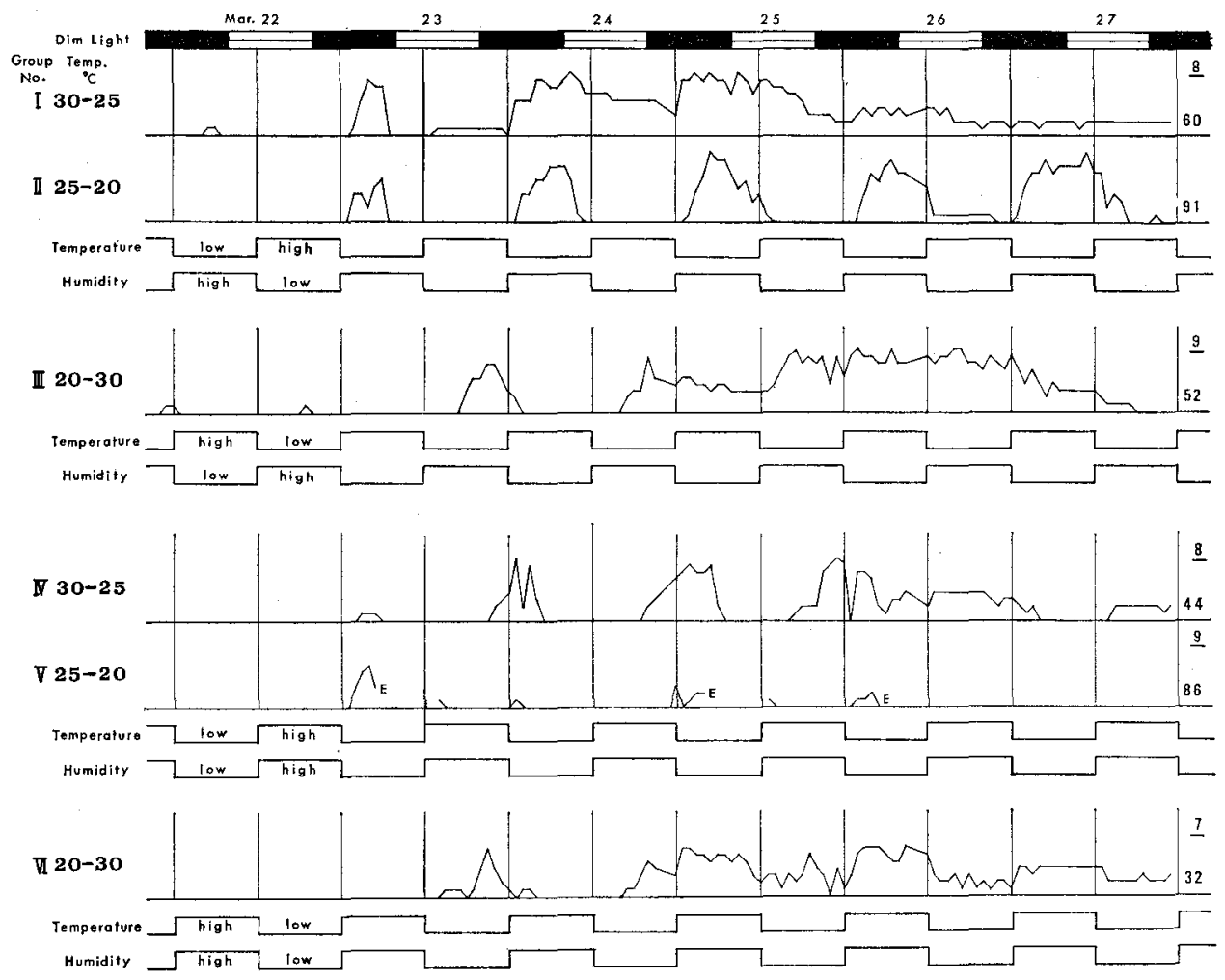

Fig. 14. Activity of Tylos under the temperature-humidity cycle.

The animals were exposed to the cycle of temperature and humidity coordinated with each other in the continuous dim light. The phase of lower temperature was combined with the highly humid phase in Groups I, II and III, but with the less humid phase in Groups IV, V and VI, and at the alternation of 30 and $25^{\circ} \mathrm{C}$ in Groups I and IV, 25 and $20^{\circ} \mathrm{C}$ in Groups II and $\mathrm{V}$, and 20 and $30^{\circ} \mathrm{C}$ in Groups III and VI.

Figures at the right end indicate at the bottom the rate of the activity in the phase of lower temperature in the last 3 days of the experiment and at the top the number of individuals killed in the experiment.

times respectively on March 23, 25 and 26, though they were regarded to be in the active phase when they took flight from the box. If this is accepted, the activity might be suggested to be in the phase of lower temperature and humidity in this group. In group VI, the activity was irregular but the rate of the activity was slightly higher in the phase of higher temperature than in the phase of lower temperature, as the rate of the activity was only $32 \%$ in the latter.

In this experiment, the activity rhythm was in general relatively obscure except for Groups II and V; evidently this was attributed to that the less humid phase at a high temperature of $30^{\circ} \mathrm{C}$ in this experiment was nearly fatal to the animals experimented with, as seen in higher mortality in Groups I, III, IV and VI, that were collected on the beach when the atmospheric temperature had been maintained in nature below $20^{\circ} \mathrm{C}$. As the animals tended to remain in the "playground" or on the surface of the pebbly hiding space before their death, the rate of the activity shculd 
be then raised in the method of activity observation adopted in the present experiments and therefore the activity rhythm reflecting such observations became superficially obscure. A clear rhythm was seen in Group II and the activity was suggested to be limited to the phase of lower temperature in Group $\mathrm{V}$ as their flight from the box should be taken in their active phase. These two groups were tested at the alternation of $25^{\circ}$ and $20^{\circ} \mathrm{C}$; this temperature cycle had been so far most effective to the activity rhythm of Tylos (Fig. 12).

\section{Summary of Experiments}

The results of above experiments may be summarized as given below: (1) The activity rhythm of Tylos granulatus can be controlled by each of the cycles of light, temperature and humidity, and the activity is seen in the phases of darkness, lower temperature and higher humidity respectively. (2) The predominance of respective cycles is dependent on the temperatures applied in each experiment. Of the temperature cycles tested, the alternation of $25^{\circ}$ and $20^{\circ} \mathrm{C}$ was the most effective and even predominated over the light cycle when this was coordinated with the temperature cycle. The humidity cycle is more effective at higher temperatures. (3) The activity rhythm of Tylos granulatus is endogenous and may persist at least for 6 days in a constant dim light and also temperature-compensated between $20^{\circ}$ and $30^{\circ} \mathrm{C}$.

\section{Conclusions and Discussions}

The behavior, physiological properties and the activity rhythm of Tylos granulatus observed or studied in the natural habitat and learned by laboratory experiments under the cycles of various environmental factors are concluded and discussed as follows.

\section{Distribution and Migration}

In Japan Tylos granulatus is reported from different beaches all over the country, and in Africa the same species has been found along the coast of South West Africa, extending from Cape Point to Ventura wreck site, $19^{\circ} 10^{\prime} \mathrm{S}-12^{\circ} 37^{\prime} \mathrm{E}$ (Kensley, 1974). The habitat substratum is similarly sandy to fairly pebbly in Japan and South West Africa (Ondo, 1952; Yuasa, 1973; Kensley, 1974), and the substratum of the beach investigated by the present author is composed of rather rough pebbles as shown in Fig. 15 and Table 1. There are some other beaches of fine sand or pobbles in the vicinity of the Seto Marine Biological Laboratory, but on these beaches Tylos has not been found so abundantly as on the studied beach at the tip of Cape Banshozaki. Actually, not so many, but some animals have occasionally been found, especially under the stones or stranded woods, on the sandy beach along the south edge of the laboratory ground (Nishimura, personal communication). Abundant occurrence of this animal on the studied beach may probably be attributed to that the beach is located at the tip of a cape far apart from the town proper as seen in Fig. 1 and is exposed to strong waves, as noticed by Kensley, that will bring there rich wracks in- 
dispensable to the life of Tylos, which will be then accumulated without being removed.

The upper limit of the natural habitat of Tylos on sandy or pebbly beaches has been defined along the landside edge of sand or pebbly areas adjoining these beaches and the lower limit around the high water mark. On the studied pebbly beach at the tip of Cape Banshozaki, the upper limit of the distribution of Tylos is seen at the edge of the pebbly area at the foot of rocky cliffs and the lower limit around the high water mark. It is known that Tylos sometimes comes up far inland, especially in a stormy weather, in fact some individuals have been found, though rarely, crawling, even in the daytime, on the laboratory floor about $50 \mathrm{~m}$ apart from the water edge across a pavement, Yuasa (1973) also recorded the migration of a tremendous number of Tylos granulatus onto the breakwater to escape typhoon waves in the daytime. Similar phenomenon was described by Tongiorgi (1969) in the relative species, Tylos latreillei. On the studied pebbly area Tylos is found abundantly around the high water mark (Fig. 1), but never in the parts flooded with the high water (Fig. 2); this agrees well with the observations of Kensley who recorded 5, 0 and 60 animals per two and half square meters respectively at the levels of $10 \mathrm{~m}$ landward from, $10 \mathrm{~m}$ seaward from and just at the high water mark at neaptides. Thus, the lower limit of the habitat fluctuates with the tides (Fig. 2), as suggested by Kensley who confirmed the range of the animal by the distribution of holes digged by Tylos on the sandy beach.

The vertical range of Tylos in the sandy or pebbly substratum in the daytime seems dependent on the condition of the substratum. On the studied beach at the tip of Cape Banshozaki many animals were found among wet pebbles just beneath the surface dry pebbly stratum, generally attaining 3 to $7 \mathrm{~cm}$ deep except for the parts composed of rather rough pebbles. While, on the sandy beach in Africa Tylos was obtained from the stratum 80 to $320 \mathrm{~mm}$ beneath the beach surface as shown by Kensley, though young animals tended to distribute nearer to the surface. The vertical reach of Tylos in the substratum will differ according to time of day (Ondo, 1953; Kensley, 1974).

The aggregation of animals at the level above the water edge of the preceding high water in the daytime (Figs. 1 and 2) and on newly stranded matters at night (Fig. 16, Table 4) may suggest the seaward migration for feeding after sunset and the landward retreat to hide themselves among pebbles before sunrise, actually the present author has occasionally observed on the studied beach some individuals moving down to the water edge in the evening and at midnight. Such a daily migration of animals may be speculated also by next brief experiment ever made in their habitat to see their selective ability of direction of $T y$ los put at the center of a plate set horizontally on the pebbly beach. The animals showed a trend to take the seaward direction at night, but the landward direction in the daytime, though a relatively strong wind blowing from the sea in the daytime and some faint lights from boats for lamp fishing at night might have affected somewhat their behaviors (unpublished data). However, a quite opposite migration is reported in an allied species, Tylos latreillei, with the landward migration at 22:00 to 23:00 and the seaward retreat at 4:00 (Tongiorgi, 


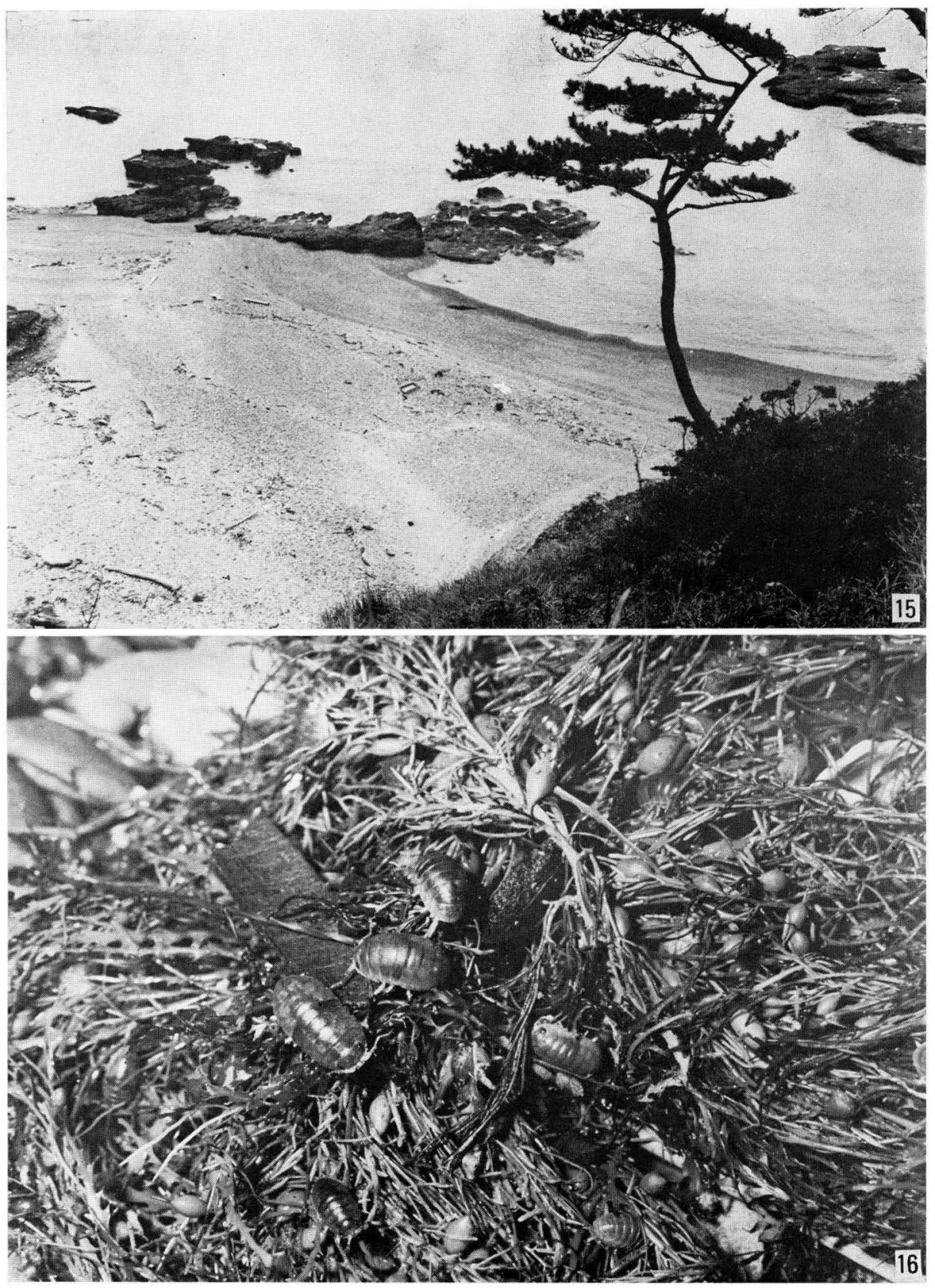

Fig. 15. The beach studied at the tip of Cape Banshozaki in the west of the Seto Marine Biological Laboratory, looked down from the cliff edge.

Fig. 16. Tylos granulatus Miers gathering to stranded Sargassum at night. 

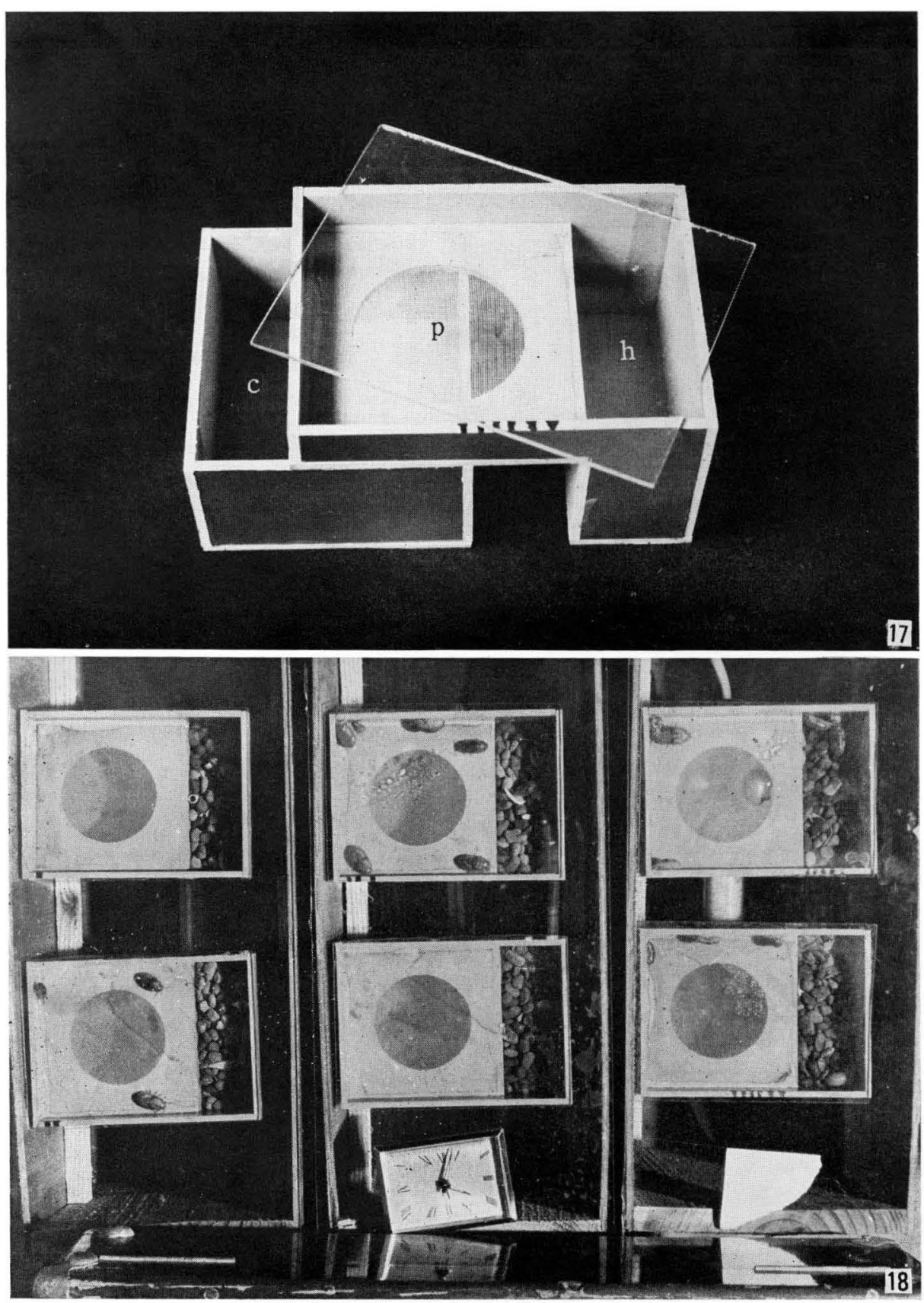

Fig. 17. The test box for recording the activity of Tylos.

The box was composed of a "playground" (P) and a hiding space (h) filled with pebbles to the bottom. The humidity inside the test box was controlled by changing the element in the humidity controlling chamber (c) set under the "playground".

Fig. 18. One of a series of pictures taken at the interval of an hour to read the number of active individuals.

The right two boxes were maintained at $20^{\circ} \mathrm{C}$, the middle two at $25^{\circ} \mathrm{C}$, and the left two at $30^{\circ} \mathrm{C}$. 
1969). Furthermore, it is stated that the direction selected by Tylos latreillei is seemingly determined by the envirormental condition, as the seaward migration is seen in the dry air, while the landward in the wet condition (Pardi, 1954). It is needed to check this signifficant behavioral difference between Tylos granulatus and T. latreillei in future works.

\section{Nocturnal Activity and its Ecolgical Significance}

The nocturnal activity of Tylos granulatus has been referred to already by Ondo (1952) and Kensley (1974) and ascertained also by the present author himself (Tables 3 and 4). Especially, Ondo (1954) showed by the laboratory experiment in the natural light and temperature condition that the small animals in this species were somewhat active even in the daytime, though the activity of grownups was seen restrictedly at night; this may explain some activity of small animals in the daytime in their habitat in the present observations (Table 3), though they were never found exposed in the daytime on the surface of dry stranded algae (Table 4).

In the course of present observations, the present author felt that the activity of Tylos granulatus might be higher in the spring tide, though this might be attributed to that his midnight observations in low water were obligatorily made in the spring tide in the site of observation, Shirahama, in Japan, as a higher activity was observed by Kensley (1974) in the same species at the time of low tide. In addition to the tidal rhythm, the lunar rhythm with a period of 14 days was suggested by Kensley (1974).

The nocturnal behavior of Tylos granulatus must be of some adaptive significance for a life in the condition reminiscent of a descert. As seen in Table 4, the temperature on the pebbly beach is much higher, sometimes over $30^{\circ} \mathrm{C}$ in the summer season, in the daytime than at night. The relative humidity is generally lower in the daytime and the light intensity in the daytime is apparently much over the upper limit for positive phototaxis of this animal. Of these, the humidity and the temperature, especially the former, are thought to be most significant for the activity of Tylos that will die in a short time in drought (Figs. 4, 5 and Table 7). The rate of water loss through the general body integuments and especially the respiratory organ (pleopods) depends not only on the relative humidity but also on the temperature, as the rate is accelerated by temperature rise even at the same relative humidity (Lockwood, 1968). Water loss by evaporation might be inevitable to prevent rising of the body temperature to some extent at higher temperatures.

On the other hand, the light itself does not seem perilous to Tylos, because this animal can stand the continuous exposure to a bright light of about 10,000 lux for more than 2 days without any serious effects, although it is unknown whether or not the direct sun light has any minor delitescent effects on the animal. Anyhow, it is apparent that the prevention of water loss is much more important to this animal than to avoid the strong light, as is shown by the results of the experiment that the animals survived longer in the watered vessel than in drought in the exposure to the direct sun light (Table 7).

The relation between the nocturnal activity and the rate of water loss has been 
discussed in some crustaceans and seemingly reached a trend that the higher the rate is, the more the nocturnal activity is kept strictly (Edney, 1951; Cloudsley-Thompson, 1961). Many of other small animals living on sandy or pebbly beaches seem to be nocturnal or crepuscular, as actually sand hoppers, sow bugs and earwigs are found on the studied beach at night, though some small flies and spiders are sometimes active in the daytime. Such a difference in the activity is clearly attributable to the difference in the essential structure of the integument and the respiratory organ that are respectively protected by impermeable waxes and consisting of spiracular components in the diurnal species (Edney, 1951).

As mentioned above, the activity of Tylos granulatus is sufficiently explainable in relation with the physical environmental factors, though evidently it is also related to some extent with the biological factors in the habitat. The frog or toad has been said to be one of the significant predators for Tylos. In fact, toads have been sometimes seen on the studied beach at night. Yuasa reported that seven individuals of Tylos were found in the stomach content of a toad together with 70 earwigs. However, the nocturnal activity of Tylos can not be a relief from this predation as the toads are also nocturnal. Some birds are seen on the studied beach in the morning, daytime or early evening and some of them are found pecking something there, though Tylos is rarely found on the beach surface at such time. Therefore, the nocturnal activity of Tylos could be regarded to some extent as adaptive to the feeding habit of the birds. However, it can be concluded that the physical factors are much more serious to Tylos granulatus than the biological facotrs, because the animal can not survive more than 2 hours on the beach in the daytime (Table 7).

\section{Control Factors of Activity}

The endogenous nature of Tylos granulatus has been suggested already by Ondo (1953) and Kensley (1974) and here it is confirmed by the present author (Fig. 8) that the rhythm of about 24 hours will persist as long as 6 days in the constant dim light and is also temperature-compensated, as in various animals and plants (Sweeney and Hastings, 1960; Imafuku, 1973), in the temperature range of $20-30^{\circ} \mathrm{C}$, in which the normal activity is observed (Fig. 3). The magnitude of the endogenous component of rhythms will be expressed by the time needed for the phase reversion (Mori, personal communication) and this was checked and compared among various animals from protozoa to vertebrates (Mori, 1944; Imafuku, 1975a and 1975b). The activity rhythm of $T y$ los may be regarded as of strong endogenous component, because the main activity of Tylos was reversed easily, but it required more than 8 days to achieve the perfect synchronization (Fig. 9).

In a series of experiments of various cycles, many animals were killed in the dry condition (Figs. 7, 8, 11, 13 and 14) and they showed just before death an abnormal behavior; and this made the analysis of the effect of various cycles difficult in the present method of experiments. In the light cycle (Fig. 7), Tylos showed a normal activity in the dark phase at the temperatures below $30^{\circ} \mathrm{C}$, but became somewhat active even in the light phase at $33^{\circ} \mathrm{C}$. This might be regarded as a kind of adaptive 
behavior to search for other better hiding-places to survive at sucn a high temperature. Below $30^{\circ} \mathrm{C}$, the animals showed in the present experiment only a single peak of the activity in the dark phase of the light cycle. However, seemingly two peaks of the activity were recorded by Ondo (1954), one at the begining and the other at the end of the dark phase. This may be attributed to the conditions that the experiments of Ondo were made in the laboratory but under the natural light and temperature cycles instead of being done under the sharp alternation of continuous 12-hour light and continuous 12-hour darkness as in the present experiments. Furthermore, the active phase in the natural habitat is said to be limited within only two hours of the time of low water at night (Kensley, 1974). All these findings by other workers indicate evidently that the rhythm observed under the artificial laboratory conditions does not always represent the natural one.

Under the temperature cycle consisting of the alternation of $20^{\circ}$ and $25^{\circ} \mathrm{C}$ or $20^{\circ}$ and $30^{\circ} \mathrm{C}$, the activity of Tylos was seen in the phase of lower temperature. Generally saying, the nocturnal animals tend to be active in the phase of lower temperature at the alternation of two different temperatures in the constant light or dark condition, as seen in rats (Calhoun, 1945), insects (Scott, 1936; Bentley et al., 1942; Roberts, 1962) and millipedes (Cloudsley-Thompson, 1951). In the case of diurnal species, the active phase is seen in the wamer temperature phase of the temperature cycle (Pauming, quoted by Bruce, 1960; Hoffmann, 1968). In the case of a nocturnal seapen, Cavernularia obesa, however, the activity (expansion) is seen at higher temperature when the colony is exposed to the alternation of $13^{\circ}$ and $19^{\circ} \mathrm{C}$, but at lower temperature when the alternation of $24^{\circ}$ and $31^{\circ} \mathrm{C}$ is applied (Imafuku, unpublished data). It is suggestible that the nocturnal animal will be active in the phase of lower temperature when it is exposed to the alternation of temperatures within the normal range for respective species. However, the activity rhythm of cockroach failed to be applied to this generalization, the active phase of this nocturnal animal was seen in the warmer phase of temperature-cycle (Roberts, 1962).

In the cycle of relative humidity, the activity was seen in the highly humid phase. This is clearly adaptive, as discussed already.

When Tylos was exposed to the cycle of temperature and light coordinated with each other, it followed the light cycle or the temperature cycle according to the range of applied temperatures. At the alternation of $25^{\circ}$ and $20^{\circ} \mathrm{C}$, the temperature cycle was more effective than the light cycle. Generally the light cycle is regarded as the most effective "Zeitgeber" and this is true in the case of the sea-pen, the active state of which is induced in the dark phase regardless of the phase of temperature cycle and the range of applied temperatures (Imafuku, unpublished data). Thus, the relative effect of respective cycles is dependent on the specificity of the animals experimented with and the environmental conditions in which they live.

When the cycles of light and humidity were given in a coordination with each other in the state that the dark phase was combined with the highly humid phase as in nature, a clear rhythm was manifested, of course with the activity in the dark phase. However, when one of the above-mentioned two cycles was shifted by 12 hours 
from the preceding state so that the darkness and lower humidity were combined, the activity rhythm became relatively irregular, though the rhythm was determined by the light cycle at lower temperatures. This might suggest that the light and humidity cycles influence the activity of Tylos nearly equally, though the humidity will affect more at higher temperatures.

When Tylos was exposed to the cycle of temperature and humidity coordinated with each other, the activity was rather irregular even when the lower temperature was joined with the phase of higher humidity. The exact cause is still unknown, though it is possible that the exposure to the state of higher temperature and lower humidity at intervals of 12 hours is harmful to this animal, as the similarly rather irregular rhythm was again observed in the repeated expeiment and a higher mortality was recorded in the present experiment.

The three cycles of light, temperature and humidity could respectively control the activity rhythm of Tylos granulatus, but their relative predominance was different according to the range of temperatures applied in each experiment.

\section{A Suggestion}

Thus, the nocturnal activity of Tylos granulatus must be significant to prevent this terrestrial animal adapted only imperfectly to the life on the beach from water-loss; it will be killed in a few hours if it is exposed to the daytime circumstances on the beach. Therefore, it is quite natural that this animal reacts to the change of humidity and follows the humidity cycle as well as the temperature cycle closely related to water loss. On the other hand, the animal follows also the light cycle and is inactive, though not always, in the light phase even when the ambient air is fully to permit the activity of the animal. On the contrary, the animal may be active in the dark phase even in the dry condition, following the light cycle and ignoring the humidity cycle at relatively lower temperatures, probably as evaporation is then depressed. If the conservation of water is the first importance to the animals and the light is never seriously influential, as this was suggested in the above experiments, Tylos does not need to react to the light cycle and it had better follow solely the humidity cycle. However, in reality the animal reacts to both the light cycle and the humidity cycle. This may by explained speculatively by the fact that in the natural habitat of Tylos the highly humid condition appears regularly at night and therefore a mechanism has developed in Tylos to react to the light cycle, the most stable environmental periodicity, as well as to the humidity cycle in the course of evolution in which the animals has been exposed for a long time to the constant alternation of light-dry and dark-moist conditions. Or, such a mechanism might be born in the short course of ontogeny as learning or something like imprinting.

Recent investigations have revealed the genetic nature of rhythmic phenomena in some animals and plants. It has been reported that normal rhythms (Browman, 1952; Aschoff, 1955; Ascoff and Meyer-Lohmann, 1954; Hoffmann, 1957 and 1959; Wahl, 1932; Scott, 1936; Bünning, 1935a, 1935b) or correct direction finding by using the biological clock (Hoffmann, 1953; Pardi, 1960) was displayed by the organisms 
kept in a constant condition or without permitting to see the sun for one to several generations. Such genetic nature of the rhythmic behavior is known also of the tidal rhythm of crabs (Williams et al., 1967). Similar behaviors are known in the organisms grown up even in the abnormal light cycles from the earliest stage of development (Hemmingsen and Krarup 1937, quoted by Bünning, 1973; Hoffmann, 1957 and 1959; Bünning, 1932). All these results may suggest that the behavior of Tylos to react to both cycles of light and humidity is genetical, although further experiments appropriately designed, for instance keeping Tylos in a constant condition from the egg state, are required prior to the decisive conclusion.

\section{Acknowledgements}

The present author wishes to express his sincere gratitude to Prof. Masaru Kato of Kyoto University, under whose supervision this work has been carried on, to the staff of the Seto Marine Biological Laboratory for affording the author every facility for the works at the laboratory, especially to Prof. Takasi Tokioka for his help to complete the manuscript, and also to Mr. Torao Yamamoto for his kindness in identifying the organisms related to the life of Tylos.

\section{REFERENCES}

Aschoff, J. 1955. Tagesperiodik bei Mäusestämmen unter konstanten Umgebungsbedingungen. Pflügers Archiv, 262, 51-59.

- and Meyer-Lohmann, J. 1954. Angeborene 24-Stunden-Periodik beim Kücken. Ibid., $260,170-176$.

Bentley, E.W., Gunn, D.L. and Ewer, D.W. 1942. The biology and behaviour of Ptinus tectus Boie. (Coleoptera, Ptinidae), a pest of stored products. I. The daily rhythm of locomotory activity, especially in relation to light and temperature. J. exp. Biol., 18, 182-195.

Browman, L.G. 1952. Artificial sixteen-hour day activity rhythms in the white rat. Amer. J. Physiol., $168,694-697$.

Bruce, V.G. 1960. Environmental entrainment of circadian rhythms. Cold Spring Harbor Symp. quant. Biol., 25, 29-48.

Bünning, E. 1932. Ủber die Erblichkeit der Tagesperiodizität bei den Phseolus-Blättern. Jahrb. wiss. Bot., 77, 283-320.

_- 1935a. Zur Kenntnis der endogenen Tagesrhythmik bei Insekten und Pflanzen. Ber. dtsch. bot. Ges., 53, 594-623.

-__ 1935b. Zur Kenntnis der erblichen Tagesperiodizität bei den Primärblättern von Phaseolus multiflorus. Jahrb. wiss. Bot., 81, 411-418.

1973. "The Physiological Clock"' Rev. 3rd Ed. The English Universities Press, London.

Calhoun, J.B. 1945. Diel activity rhythms of the rodents, Microtus ochrogaster and Sigmodon hispidus. Ecology, 26, 251-273.

Cloudsley-Thompson, J.L. 1951. Studies in diurnal rhythms. I. Rhythmic behaviour in millipedes. J. exp. Biol., 28, 165-172.

1961. "Rhythmic Activity in Animal Physiology and Behaviour". Academic Press, New York \& London.

Edney, E.B. 1951. The evaporation of water from woodlice and the millipede Glomeris. J. exp. Biol., 28, 91-115.

Hoffmann, K. 1953. Die Finrechnung der Sonnenwanderung bei der Richtungsweisung des sonnenlos aufgezogenen Stares. Naturwiss., 40, 148.

1957. Angeborene Tagesperiodik bei Eidechsen. Naturwiss., 44, 359-360.

1959. Die Aktivitätsperiodik von im 18- und 36-Stunden-Tag erbrüteten Eidechsen. Z. 
vergl. Physiol., 42, 422-432.

1968. Temperaturcyclen als Zeitgeber der circadianen Periodik. Verh. d. Dtsch. Zool., 18, 265-274.

Iga, T. 1972. Circular movement of Tylos granulatus. Zool. Mag., 81, 408. (In Japanese).

Imafuku, M. 1973. On some physiological aspects in the daily rhythmic activity of the sea-pen, Cavernularia obesa Valenciennes. Publ. Seto Mar. Biol. Lab., 20 (Proc. Second Internat. Symp. Cnidaria), 431-454.

1975a. Peristalsis in the monopolypid stage of the sea-pen, Cavernularia obesa Valenciennes. Ibid., 22, 195-216.

1975b. Adaptation of the circadian rhythm of mating-reactivity to abnormal light-dark cycles in Paramecium bursaria. J. interdiscipl. Cycle Res., 6, 141-151.

Kensley, B. 1974. Aspects of the biology and ecology of the genus Tylos Latreille. Ann. S. Afr. Mus., $65,401-471$.

Lockwood, A.P.M. 1968. "Aspects of the Physiology of Crustacea". Oliver and Boyd, Edinburgh \& London.

Mori, S. 1944. Daily rhythmic activity of the sea-pen, Cavernularia obesa Valenciennes. III. Controlling of the activity by light (1). Zool. Mag., 56, 1-5. (In Japanese).

Ondo, Y., 1952. A behavioral and ecological study of Tylos granulatus Miers. Ibid., 61, 55. (In Japanese).

1953. Daily rhythmic activity of Tylos granulatus Miers. II. On some environmental elements to induce the nocturnal activity of the animals. J. Fac. Educ. Tottori Univ. Nat. Sci., 4, 20-23. (In Japanese with English rèsumé).

1954. do. III. Modification of rhythmic activity in accord with its growing stage. Jap. J. Ecol., 4, 1-3. (In Japanese with English rèsumé).

Pardi, L. 1954. Über die Orientierung von Tylos latreillii Aus. and Sav. (Isopoda terrestria). Z. Tierpsychol., 11, 175-181.

- 1960. Innate components in the solar orientation of littoral amphipods. Cold Spring Harbor Symp. quant. Biol., 25, 395-401.

Roberts, S.K. 1962. Circadian activity rhythms in cockroaches. II. Entrainment and phase shifting. J. cell comp. Physiol., 59, 175-186.

Scott, W.N. 1936. An experimental analysis of the factors governing the hour of emergence of adult insects from their pupae. Trans. R. Ent. Soc. Lond., 85, 303-329.

Sweeney, B.M. and Hastings, J.W. 1960. Effects of temperature upon diurnal rhythms. Cold Spring Harbor Symp. quant. Biol., 25, 87-104.

Tongiorgi, P. 1969. Ricerche ecologiche sugli artropodi di una spiaggia sabbiosa del litorale tirrenico: III. Migrazioni e ritmo di attività locomotoria nell'isopode Tylos latreilli (Aud. and Sav.) e nei tenebrionidi Phaleria provincialis Fauv. e Halammobia pellucida Herbst. Redia, 51, 1-19.

Wahl, O. 1932. Neue Untersuchungen über das Zeitgedächtnis der Bienen. Z. vergl. Physiol., 16, 529-589.

Williams, B.G. and Naylor, E. 1967. Spontaneously induced rhythm of tidal periodicity in laboratory-reared Carcinus. J. exp. Biol., 47, 229-234.

Yuasa, Y. 1973. Beach cleaner, Tylos granulatus. Yama no Ue no Sakanatachi, Himeji Gity Aquarium, no. 12 Jan. 1973. (In Japanese). 